\title{
The absorption of stearic acid from triacylglycerols: an inquiry and analysis
}

\author{
Geoffrey Livesey \\ Independent Nutrition Logic, Pealerswell House, Wymondham, Norfolk, NR18 OQX, UK
}

\begin{abstract}
Although stearic acid is a saturated fatty acid, its influence on plasma cholesterol acid other health variables is neutral; possibly owing in part to poor absorption. Reduced absorption of stearic acid from particular triacylglycerols, cocoa butter and novel fats formulated with short- and longchain acid triacylglycerol molecules (Salatrims) has been attributed to high intakes. However, the circumstances and causes of poor stearic acid digestion from triacylglycerols are unclear; published data were therefore collected and analysed, with emphasis on human studies. Of twenty-eight studies conducted in adults, most are in men $(>90 \%)$. The assertion that reduced absorption is due to a high intake of stearoyl groups is not supported: dietary intakes of stearoyl of $0.05-0.65 \mathrm{~g}$ stearic acid equivalent/ $\mathrm{kg}$ body weight (cf typical intake of $0.2 \mathrm{~g}$ stearic acid equivalent $/ \mathrm{kg}$ body weight in the Western diet) indicate that the 'true' digestibility of stearoyl is 0.98 (SE 0.01) g/g, with apparent digestibility less than this value at low intakes owing to endogenous stearic acid excretion and to inter-publication variation of unidentified cause. The neutral health impact of stearic acid must be due to factors other than availability. Exceptions include cocoa butter, Salatrims and tristearin, for which digestibility is an additional factor. The efficiency with which human subjects digest stearoyl from cocoa butter still remains uncertain, while the digestion of total longchain fat from this source is $0.89-0.95 \mathrm{~g} / \mathrm{g}$, high in comparison with $0.33 \mathrm{~g} / \mathrm{g}$ for Salatrim 23CA and $0.15 \mathrm{~g} / \mathrm{g}$ for tristearin in their prepared states. Salatrims contain the highest proportion of long-chain fatty acids that are stearic acid-rich other than tristearin, which is the main component of fully-hydrogenated soyabean and rapeseed oil. Analysis shows that apparent digestibility of stearic acid is associated with stearoyl density within the triacylglycerol molecule and that, in Salatrims, the occurrence of short-chain fatty acids in place of long-chain fatty acids increases this density. Soap formation appears not to be a major factor in the reduced digestion of stearic acid from tristearin under regular dietary circumstances, but both microcrystallinity and reduced digestibility of tri-, diand monostearoylglycerols appears to be important. Solubilisation of high-melting-point tristearin in low-melting-point oils improves the
\end{abstract}

\footnotetext{
Abbreviations: OOS, 1,2-dioleoyl 3-stearoylglycerol; OSO, 1,3-dioleoyl 2-stearoylglycerol; OSS, 1-oleoyl 2,3distearoylglycerol; SBS, 1,3-stearoyl 2-butyrylglycerol; S:L, short-chain organic acids:long-chain saturated fatty acids; SOS, 1,3-stearoyl 2-oleoylglycerol; SSB, 1,2-stearoyl 3-butyrylglycerol.
}

Corresponding author: Dr Geoffrey Livesey, fax +44 1953 600218, email glivesey@inlogic.co.uk 
digestibility of its stearic acid, particularly when emulsified or liquidized at above melting point. However, without such artificial aids, the digestive tracts of the rat, dog and man have a low capacity for emulsifying and digesting stearic acid from tristearin. Reduced digestibility of stearic acid from Salatrim 23CA also appears to be attributable to reduced digestibility of di- and monostearoylglycerols and is particularly due to remnants with the 1- or 3-stearoylglycerol intact after initial hydrolytic cleavage. Shortchain organic acid in Salatrim 23CA, which is readily hydrolysed, leaves such remnants. Unlike tristearin, Salatrim 23CA melts at body temperature and mixing it with low-melting-point oils is not expected to cause further disruption of microcrystalline structures to aid digestibility of its stearoyl groups. The low digestibility of stearoyl in Salatrim 23CA, together with the occurrence of short-chain organic acids in this product, account for its relatively low nutritional energy value (about $20 \mathrm{~kJ}(5 \mathrm{kcal}) / \mathrm{g}$ ) compared with traditional fats $(37 \mathrm{~kJ}(9 \mathrm{kcal}) / \mathrm{g})$ and low fat value $(<20: 37 \mathrm{~kJ} / \mathrm{kJ}$; $<5: 9 \mathrm{kcal} / \mathrm{kcal})$ relative to traditional fats. In part these differences are because of minor effects of Salatrim 23CA on the excretion of other fat and protein, due to the bulking properties of this poorly-digestible fat.

\section{Stearic acid: Dietary fat: Salatrim: Digestibility: Short-chain organic acids}

\section{Introduction}

Despite a century of research on the digestion of stearic acid present in dietary triacylglycerols, since Arnschink (1890) showed that tristearin (tristearoylglycerol) could be poorly digested in dogs, a great deal of uncertainty remains about the factors that determine the extent of stearic acid digestion in human subjects and experimental animals.

By 1994, the importance of and interest in this saturated fatty acid had grown greatly, to include, that year, two major symposia and a significant collection of publications. These examined, first, the uniqueness of stearic acid relative to other long-chain fatty acids with respect to the metabolic consequences of its consumption (Pearson, 1994a) and second, the implications of stearic acid in chocolate (Pearson, 1994b). The publications brought together the available information on stearic acid in novel fats, particularly those formulated with shortand long-chain acid triacylglycerol molecules (Salatrims: Liener, 1994). Amongst the nutrition and health issues arising have been the relatively minor or neutral role of stearoyl-containing triacylglycerols in cholesterogenicity (Grande et al. 1970; Grundy, 1994), thrombogenicity (Hoak, 1994), atherogenicity (Kritchevsky, 1994; Woollett \& Dietschy, 1994; Decker, 1996), digestibility (Bracco, 1994; Hayes et al. 1994b) and energy value (Finley et al. 1994a,b; Ranhotra et al. 1998).

The low and neutral effects of stearic acid (18:0) on metabolism compared with, for example, palmitic acid (16:0) has been attributed in part to reduced digestion and absorption (Grande et al. 1970; Apgar et al. 1987; Mitchell et al. 1989; Kritchevsky, 1994; Decker, 1996) and, amongst other possible reasons, to the conversion of absorbed stearic to oleic acid (Bonanome \& Grundy, 1988; Emken et al. 1993; Grundy, 1994). The relative significance of these two processes in the neutralization of stearic acid remains unclear (Emken, 1994; Rhee et al. 1997), but the composition of chylomicrons is clearly affected by the extent of stearic acid absorption (Bracco, 1994), as is the serum lipid content in men in whom saturated fat 
absorption is reduced by highly fortifying the diet with Ca (Denke et al. 1993). However, inferences about stearic acid absorption that are based on the fatty acid composition of plasma chylomicrons would seem to be unsound, because of the major contribution of endogenous lipids introduced into chylomicrons in the small intestine, which may lead to conflicting interpretation of the experimental data (Grande et al. 1970; Bonanome \& Grundy, 1989).

The structural and some physical aspects of triacylglycerols that determine fat digestibility have received considerable attention (Tomarelli et al. 1968; Small, 1991,1992; Bracco, 1994; Emken, 1994; Decker, 1996), but the information remains incomplete. To date there has been no detailed analysis of published data, either to assess the frequency and circumstance of reduced stearic acid digestion from triacylglycerols in traditional foodstuffs, and novel fats, or to uncover the factors that determine such digestibility, as given. Such a lack of information has reinforced doubt or speculation about stearic acid digestion, for example: about the causes of reduced digestion when this occurs (Decker, 1996; McDonell, 1997); about the occurrence of reduced digestion in human subjects in relation to certain structured triacylglycerols (World Health Organization, 1999); about the predictability of stearic acid digestibility for triacylglycerols with related structures (World Health Organization, 1999); about the methodology underlying observations of reduced stearic acid digestion from traditional foodstuffs (Bonanome \& Grundy, 1988; Grundy, 1994); about whether reduced digestion of stearic acid may simply be due to high intake of this fatty acid. In addition, there has been little previous comment on the implications of stearic acid for the assessment of available fat and energy values, which is important in relation to food regulations and labelling claims.

\section{Intake and excretion of stearic acid}

\section{Traditional foods and mixed oils}

Studies in which the intake and excretion of stearic acid have been determined in adult human subjects aged 18-70 years are listed in Table 1. It is notable that for traditional sources of triacylglycerol there are few observations for female subjects (one diet) compared with male subjects (twenty-two diets). Amongst these studies, daily intakes range from 3 to $47 \mathrm{~g}$ stearic acid in triacylglycerol ( $v$. daily total fat intake range of $70-135 \mathrm{~g}$ ), and the apparent digestibility of stearic acid ranges from as low as 0.68 to as high as $0.98 \mathrm{~g} / \mathrm{g}$ intake. Typical intakes of stearic acid would be $3 \mathrm{~g} / \mathrm{d}$ (Japan) to $20 \mathrm{~g} / \mathrm{d}$ (Finland) or $15 \mathrm{~g} / \mathrm{d}$ for a typical European or USA diet (Hashim \& Babayan, 1978; Katan et al. 1994). The data in Table 1 are shown in order of publication, and shows no pattern which explains the variability in the digestibility of stearoyl constituents of triacylglycerols.

Analysis of these data shows (Fig. 1) that total stearic acid excretion reasonably fits a pattern of the form $\mathrm{y}=\mathrm{mx}+\mathrm{c}$. It might be presumed that the constant in this equation represents the endogenous stearic acid excretion that would have occurred on a fat-free (or stearoyl-free) diet. This factor was statistically significant $(P<0.01)$ at $0.009($ SE 0.002$) \mathrm{g}$ stearic acid $/ \mathrm{kg}$ body weight (equivalent to approximately $4 \%$ of the stearic acid intake on a typical European or USA diet). A shallow but statistically significant $(P<0.05)$ slope relates an increase in stearic acid excretion to an increase in exogenous stearic acid from dietary triacylglycerol. The slope is the true indigestibility of stearoyl from the diet (0.024 (SE 0.010) g/g intake) and so a value of $1-$ slope represents the true digestibility, which is 0.976 (SE 0.010$) \mathrm{g} / \mathrm{g}$ intake. The wide range in stearic acid digestibility from triacylglycerols reported in the literature, and summarised in Table 1, clearly does not reflect entirely inconsistent observations, but appears 


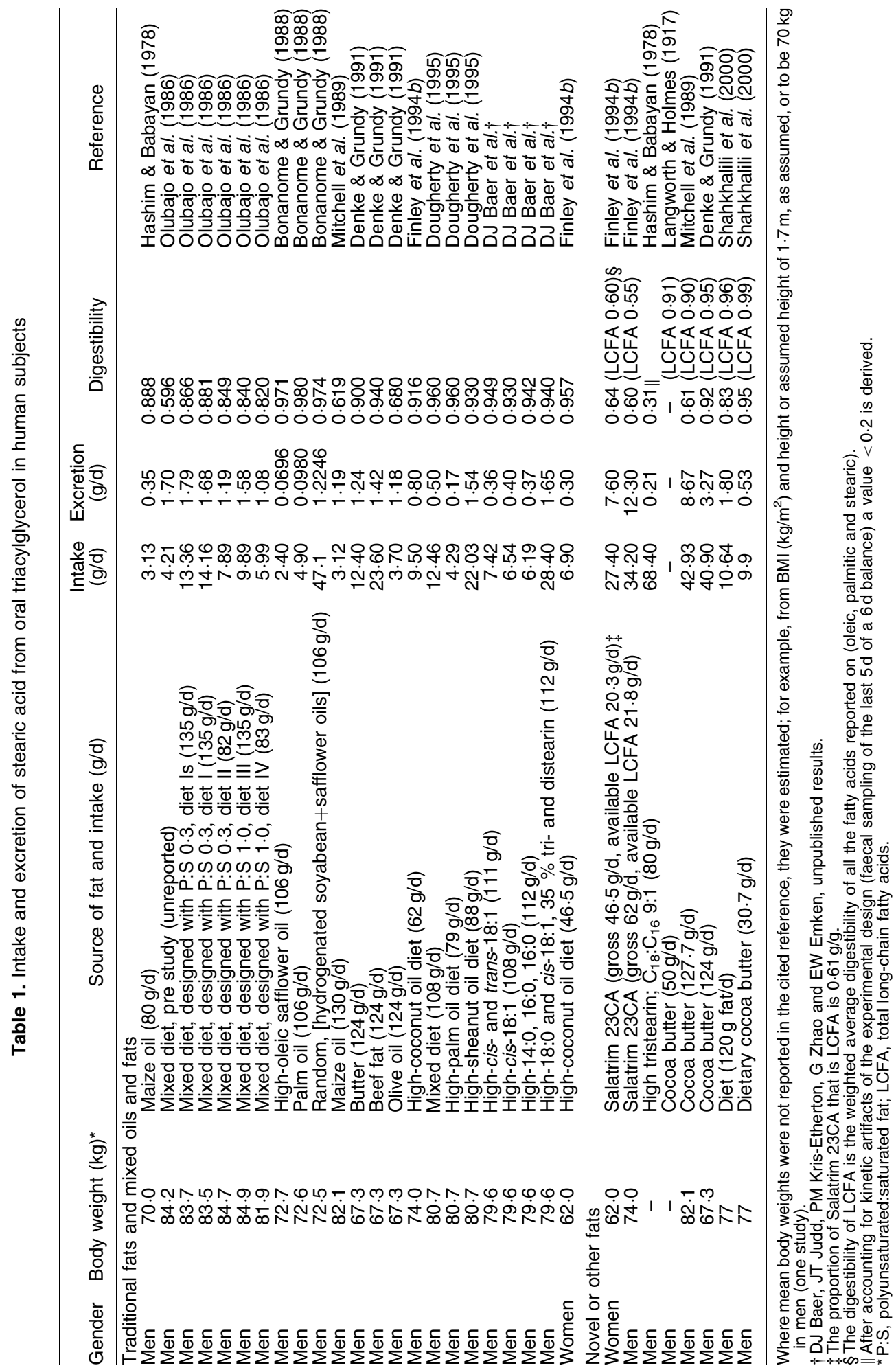




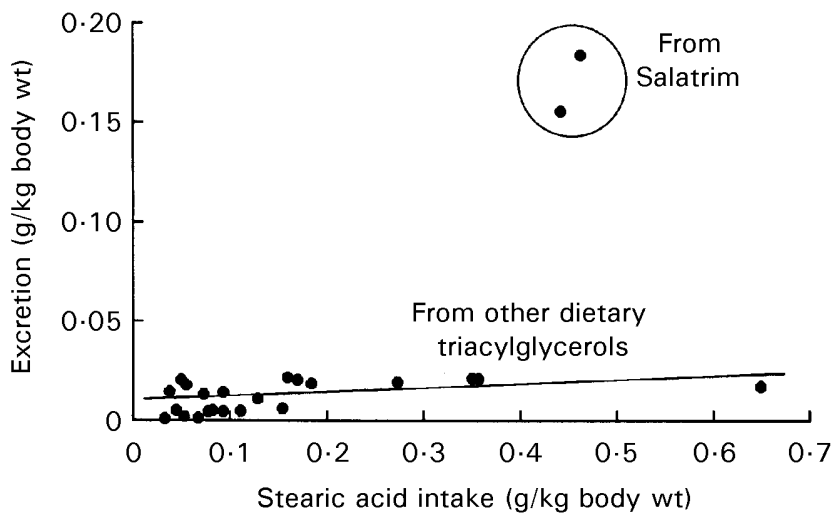

Fig. 1. Excretion of stearic acid in faeces of adults consuming triacylglycerols. Data are derived from Table 1 (excluding cocoa butter, for which stearic acid digestibility remains unclear). The regression line shown has slope 0.024 (SE 0.010) $\mathrm{g} / \mathrm{g}$ intake and intercept 0.009 (SE 0.002) $\mathrm{g} / \mathrm{kg}$ body weight. The two data points for Salatrim 23CA (a novel fat formulated with short-chain and long-chain acid triacylglycerol molecules) for men and women are significant outliers, being 20 and 24 residual SD from the regression line respectively.

to result largely from variation in stearic acid intake from triacylglycerols and excretion of endogenous stearic acid.

Replotting the intake and excretion data (Fig. 2) shows clearly that the apparent digestibility of stearic acid increases with increasing intake. The curve through these data is that predicted by the regression line in Fig. 1. There is no evidence that high intakes of stearic acid result in low apparent digestibility.

We might assume that stearoyl intake is the only determinant of variation in its apparent digestibility evident in the literature. However, plotting the residuals about the regression line

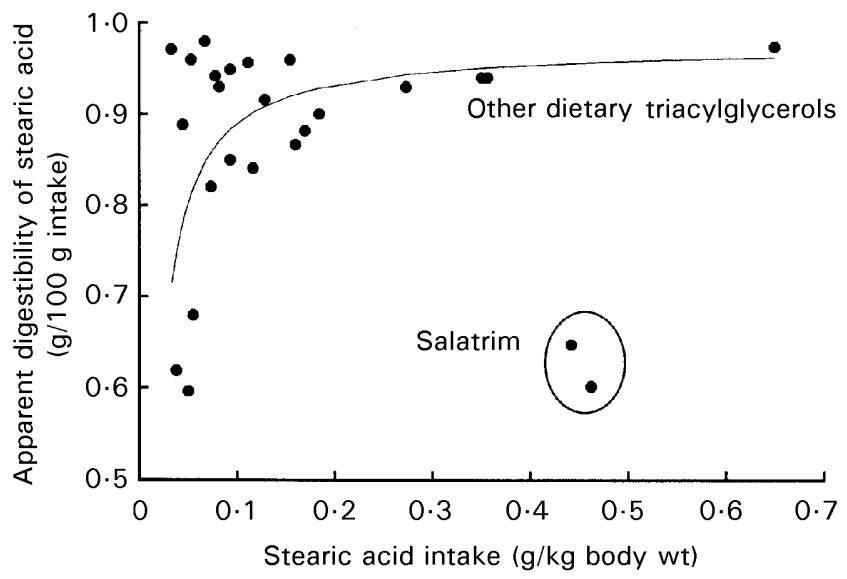

Fig. 2. Apparent digestibility of stearic acid in adults consuming triacylglycerols. Data are derived from Table 1 (excluding cocoa butter, for which stearic acid digestibility remains unclear). The curve shown is derived from the regression line in Fig. 1. The two outlying data points are those for Salatrim 23CA (a novel fat formulated with short-chain and long-chain acid triacylglycerol molecules) for men and women. 


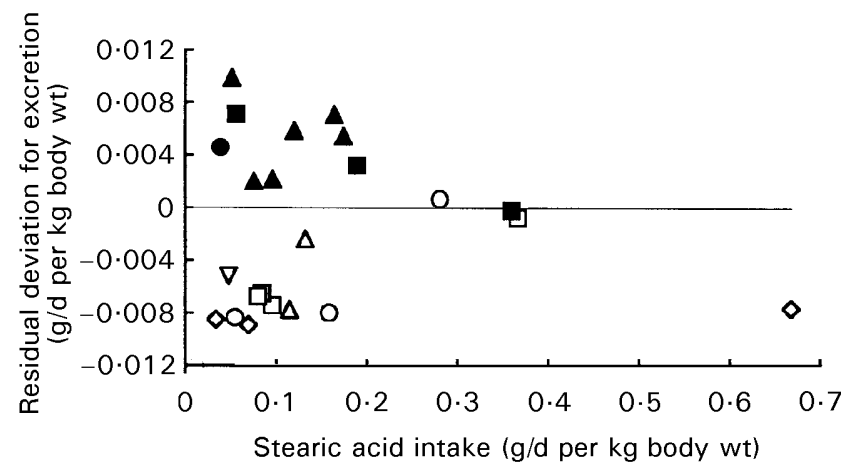

Fig. 3. Inter-publication variation in reported stearic acid excretion in adults. Data are the residuals about the regression line in Fig. 1. Observations from the same publication share a common symbol. Publications tend to have data with residuals either only above or only below zero, indicating relative bias. $(\mathbf{0}, \mathbf{\square}, \mathbf{\Delta})$ Data from publications with predominant positive

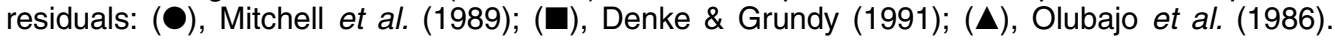
$\bigcirc, \square, \triangle, \diamond, \nabla$, Data from publications with predominant negative residuals: $(\bigcirc)$, Dougherty et al. (1995); $(\nabla)$, Hashim \& Babayan (1978); $(\triangle)$, Finley et al. (1994b); ( $\square$ ), DJ Baer, JT Judd, PM KrisEtherton, G Zhao and E W Emken, unpublished results; $(\diamond)$, Bonanome \& Grundy (1988).

of Fig. 1, publication-by-publication, shows (Fig. 3) that inter-publication differences occur in the results for stearic acid excretion. The inter-publication differences are found here to be greater than differences between treatments within publications. Thus, ANOVA shows that the root mean square between-treatment value is only $0.0035 \mathrm{~g}$ stearic acid excretion $/ \mathrm{kg}$ body weight, whereas that between publications is three times greater at $0.0096 \mathrm{~g}$ stearic acid $/ \mathrm{kg}$ body weight, where the latter is about $5 \%$ of a typical intake of approximately $0.2 \mathrm{~g}$ stearic $\mathrm{acid} / \mathrm{kg}$ body weight.

The most dissimilar residuals in Fig. 3 arise from just one laboratory, although the same experimental design, subject characteristics, faecal collection and analytical methods were used. Both studies at this laboratory used liquidized foods; although all that obviously differed was the source of visible dietary fats investigated, there was also a difference in protein, which was not being investigated for a treatment effect. Milk protein was used in one study (Bonanome \& Grundy, 1988) and soyabean protein in another study (Denke \& Grundy, 1991). The soyabean protein was associated with the higher stearic acid excretion. Thus, mean values (for three diets of varied triacylglycerol composition) showed the soyabean-protein diet to deviate from the regression line by +5.6 (SE 1.1$) \mathrm{mg}$ stearic acid/kg body weight, whereas the milkprotein diet deviated in the opposite direction, by -8.3 (SE 0.4) $\mathrm{mg}$ stearic acid/kg body weight. The role of protein source as a determinant of the digestibility of stearic and other fatty acids may warrant more direct investigation.

It is possible that some inter-publication differences in stearic acid excretion (1) reflect the choice of analytical method for the determination of stearic acid in faeces, (2) may simply be inter-laboratory differences in methods application, (3) may depend on the way in which fats and oils are presented for eating, or (4) represent combinations of the other three factors. Too little information accompanies the publications shown in Table 1 to comment on the possible impact of dietary fibre and mineral soap formation as causes of the variation seen in Figs. 1 and 2; should either occur, we would predict an elevated faecal fat excretion. After accounting for endogenous excretion of stearic acid, stearoyl intake, the possible effect of protein source, and 
remaining inter-publication differences in stearic acid excretion, it was not possible to find any significant effect of type of traditional fat source on the digestibility of stearic acid. Thus, it has been suggested that the polyunsaturated : saturated fatty acids value (Table 1) may be important (Olubajo et al. 1986), but differences in digestibility of stearic acid between diets in their studies are more closely associated with differences in stearic acid intake as triacylglycerols than P:S ratio. It should be noted, however, that there was little or no representation among the regression data (Fig. 1) of fats especially rich in stearic acid, such as cocoa butter and novel fats. A potentially-important factor is the proportion of the ingested triacylglycerol that is stearic acid, i.e. the stearoyl density of the triacylglycerol (g stearic acid/g triacylglycerol).

\section{Salatrim $23 C A$}

Figs. 1 and 2 show, in addition to the observations on traditional and mixed oils and fats, a substantial excretion and low apparent digestibility of stearic acid from the novel stearic acidrich triacylglycerol Salatrim 23CA. This triacylglycerol is one of a family of triacylglycerols that are prepared from hydrogenated soyabean or rapeseed oil and short-chain triacylglycerols by the process of randomisation such that the products comprise short- and long-chain acid triacylglycerol molecules. Salatrim 23CA is prepared from a 11:1:1 molar ratio of the shortchain organic acids acetic $\left(\mathrm{C}_{2}\right)$ and propionic $\left(\mathrm{C}_{3}\right)$, and hydrogenated rapeseed oil fatty acids which are mostly stearic acid. The predominant triacylglycerols of Salatrim 23CA are 1,2diacetyl 3-stearoylglycerol (about $40 \%$ by analysis) and 1,3-diacetyl 2-stearoylglycerol (about $20 \%$ by analysis), while the content of the poorly-digestible tristearin (tristearoylglycerol) in Salatrim 23CA is small, <0.7\% (Softly et al. 1994).

It is immediately obvious from Figs. 1 and 2 that (1) stearic acid from Salatrim 23CA is poorly digested, as reported by Finley et al. (1994a); (2) the digestion and excretion of stearic acid from this source differs substantially from that for traditional triacylglycerol sources, which is not immediately apparent from the range of stearic acid digestibilities for traditional fats, as collated in order of publication in Table 1; (3) the reduced digestion is not due to intake of a dose of stearic acid higher than that for the other fats but probably is reduced as a result of enrichment of stearic acid in this novel fat; (4), by inference, the structure and properties of the Salatrim 23CA triacylglycerols and digestion products must determine the poor digestibility of stearic acid from this source. These data comparing Salatrim 23CA of Finley et al. (1994b) with the data for traditional fats (Figs. 1 and 2) suggest that the short-chain organic acids, which as triacylglycerol would be readily digested (Wang, 1986; DeMichelle \& Karlstad, 1995), are part of the key to the low apparent digestibility of stearic acid in this novel fat.

All members of the Salatrim family have four important characteristics that determine the digestibility of its stearic acid. First, in all molecules in this family, a large proportion of the long-chain fatty acid is stearic acid. Second, stearic acid and the mono- and di-acylglycerol intermediates in the digestion of Salatrims have high melting points, so are difficult to digest (Small, 1991). Third, Salatrim fatty acids are distributed randomly, so that the stearic acid is largely (67\%) in the 1- and 3-positions on the glycerol backbone, which require hydrolysis for absorption. Fourth, Salatrim includes lower-molecular-weight short-chain organic acids that (1) increase the stearic acid density of the fat and (2) may be readily cleaved from the triacylglycerol, causing a marked change in physical properties between substrate and product. Each of these characteristics will now be considered, together with other factors. 


\section{Factors that determine stearic acid digestibility}

\section{True digestibility v. apparent digestibility: endogenous sources of faecal fatty acids}

If the only source of stearic acid in faeces were that resulting from incomplete digestion and absorption of the diet, the digestibility calculated as intake minus faecal loss expressed as a proportion of intake would be a true digestibility value. In reality, faecal stearic acid comes from a variety of endogenous sources, and so this proportion is an apparent digestibility. Factors that affect endogenous fatty acid excretion will affect the apparent digestibility of stearic acid. Faecal fatty acids are derived also from bile, pancreatic and other secretions, sloughed cells, transmucosal exudation and colonic micro-organisms (Cotton, 1972; Demarne et al. 1979), including bacterial transformation of fatty acids from all sources (Eyssen et al. 1972; Sklan \& Budowski, 1972). Early studies showed that fat is excreted in human subjects even with a fat-free diet (Lewis et al. 1954). Furthermore, although faecal fatty acid composition varies considerably between individuals, it varies little with the composition of dietary fats (Webb et al. 1963). In addition, under normal circumstances fatty acids entering the colon largely reflect the composition of the intestinal mucosa (Wiggins et al. 1969) and, when mucosal cell turnover is elevated, faecal lipid from this source has been suggested to be sufficient to constitute a state of fat-losing enteropathy (Cotton, 1972). Total lipid intake normally has only a small effect on total faecal lipids, with one study showing daily faecal lipid weight (g) to be 2.93 (SE 0.021) times the daily lipid intake (g) in human subjects (Henry, 1964). This observation for total fat excretion is mirrored by stearic acid excretion (Fig. 1).

Stearic acid has a relatively reduced digestibility in comparison with other fatty acids, even in traditional foods

Previous studies on the digestibility of fatty acids from triacylglycerols may have been confounded to some degree by the excretion of endogenously-derived fatty acids, making true digestibilities unclear. Using information available in the literature, this problem may be overcome to a considerable extent by examination of the digestibility at high intakes (where apparent digestibility becomes least dependent on endogenous excretions), or by extrapolation to high intakes based on apparent digestibilities at increasing oral doses (Fig. 4). In this way true digestibilities are derived, and for stearic acid (18:0) in the triacylglycerols of mixed diets the value is lower than that for palmitic acid (16:0), and even lower than that for myristic acid (14:0). The true digestibility of stearic acid derived in this way for data from the study of Olubajo et al. (1986) was $0 \cdot 85$, which compares with an overall value of 0.98 for that given by the regression (Fig. 1). This disparity may be due in part to unsatisfactory extrapolation and in part to overestimation of faecal fat by the gravimetric procedure used by Olubajo et al. (1986). Thus, not all the extractable material will be derivatives of fatty acids (as noted by Denke \& Grundy, 1991). Nevertheless, the data in Fig. 4 are otherwise relative, and illustrate differences in true digestibility of saturated fatty acids. If such evidence is doubtful, then fat digestion is less efficient in infants than in adults (Filer et al. 1970; Jensen et al. 1986), and so endogenous excretions may be relatively less confounding in infants than in adults. Thus, the dependency of true digestibility of triacylglycerol-fatty acid on chain length is more readily evident in infants (Fig. 5). Chain length is clearly an important factor determining fatty acid digestibility. Saturated fatty acids of chain length longer than $\mathrm{C}_{18}$ are even more poorly digested from triacylglycerols than stearic acid (Nolan, 1981; Bezard \& Sawadogo, 1983; Peters et al. 1991), 


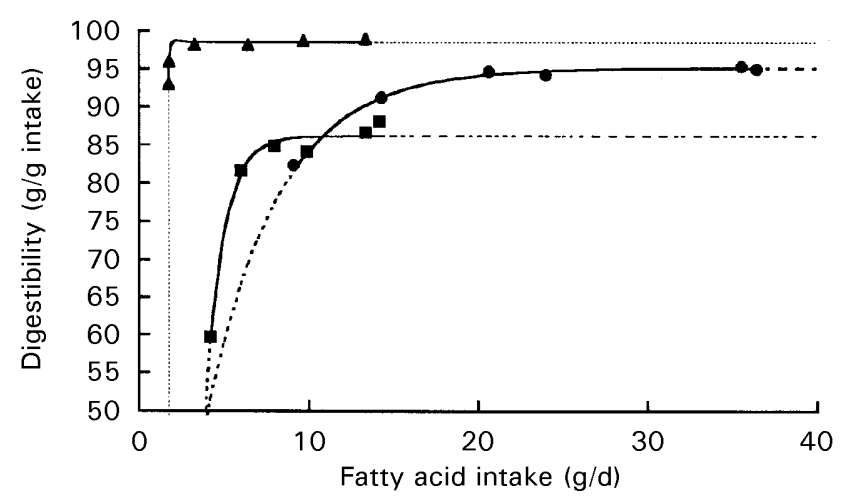

Fig. 4. Apparent digestibilities of myristic $(14: 0, \mathbf{\Delta})$ palmitic $(16: 0,0)$ and stearic acid $(18: 0$, 口) as a function of intake using data from a single report. Data are from Olubajo et al. (1986), as shown in Table 1. Curves are fitted simply, as lag-rising exponentials to the data shown.

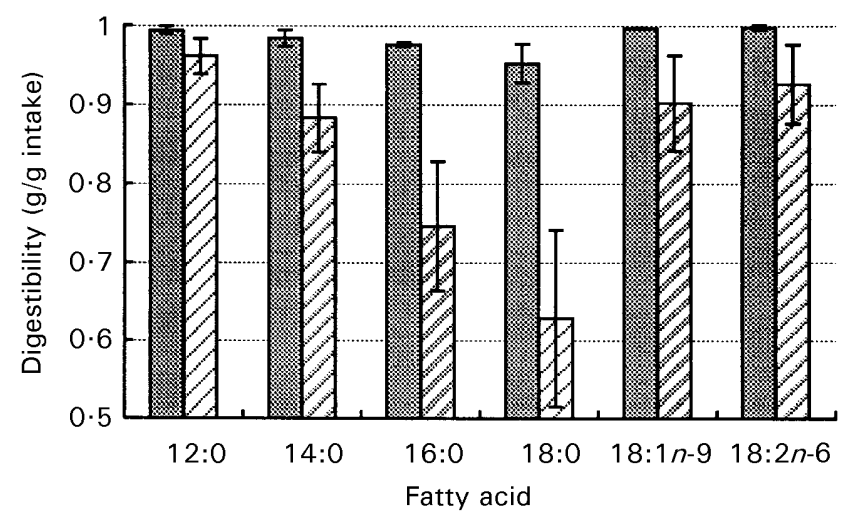

Fig. 5. Apparent digestibility of fatty acids as a function of chain length and saturation in adults and infants. ( $\square$ ), Data for adults from Dougherty et al. (1995); values are means with their standard deviations represented by vertical bars for three diets. (何) Data for a long-chain triacylglycerol formula fed to very small infants from Jensen et al. (1986); values are means with their standard errors represented by vertical bars for ten infants.

while including double bonds in the long-chain fatty acid restores digestibility in both adults and infants (Fig. 5).

The mechanisms by which chain length caused reduced digestion have not been confirmed, but are reasoned to include digestion products that precipitate as $\mathrm{H}^{+}, \mathrm{Ca}^{2+}$ and $\mathrm{Mg}^{2+}$ soaps, which would occur more readily with fatty acids of higher melting point. Thus, melting point increases with both chain length and degree of saturation of fatty acids (Small, 1991), as does the indigestibility of fatty acids in triacylglycerols (Figs. 4 and 5). A further possibility is the formation during digestion of high-melting-point acylglycerols, which like the soaps melt at higher temperatures with increasing chain length and saturation (Small, 1991). Mineral soaps rather than free acids occur at neutral $\mathrm{pH}$ (within the intestinal $\mathrm{pH}$ range); indigestibility of stearic acid (when this occurs) is therefore more likely to be due to the formation of either mineral soaps or insoluble acylglycerols. The latter probably have more significance than previously considered, as will be exemplified later (see pp. 194-198 and 203). 
Fatty acid distribution on the glycerol backbone: the significance of acylglycerols in addition to soaps

It is well established that the fatty acid ester linkages present in the sn- 1 or sn-3 position of the glycerol backbone are more readily hydrolysed than those at the sn- 2 position. This factor has been attributed to the specificity of pancreatic lipase and soap formation from fatty acids released from these positions, while sn-2 fatty acids give rise to 2-monoacylglycerols that can be readily absorbed (Small, 1991; Bracco, 1994). Moreover, melting point and solubility in the lipid phase of substrate triacylglycerol is a significant factor affecting digestion (Small, 1991), but there has been less consideration of this factor as a determinant of the further digestion and absorption of intermediates. The relative significance of soap formation $v$. the formation of insoluble acylglycerols also seems to have escaped significant discussion in previous publications.

Mattson et al. (1979) provide relevant data showing the importance of poorly-digestible acylglycerol intermediates after confounding by soap formation is minimised. This interpretation appears to have been missed, or now goes unrecognised by the focus on soap formation, high-Ca diets that prompt soap formation, and possibly by considering 1,2- and 2,3diacylglycerol products as being equivalent, which as products of lipase digestion in vivo they may not be. The following interpretation provides an additional and potentially more important mechanism for reduced digestibility.

When $\mathrm{Ca}^{2+}$ - and $\mathrm{Mg}^{2+}$-deficient rat diets were used to reduce the possibility of soap formation, the synthetic triacylglycerols 1,3-dioleoyl 2-stearoylglycerol (OSO), 1,2-dioleoyl 3-stearoylglycerol (OOS), 1,3-distearoyl 2-oleoylglycerol (SOS) and 1-oleoyl 2,3-distearoylglycerol (OSS) were readily hydrolysed, as indicated by the cleavage of their constituent oleic acid ( $>93 \%$ in each case; see Table 2). The reduced digestion of stearic acid from some of the triacylglycerols (Table 2) is therefore due to poor hydrolysis or absorption of first- or second-cleavage products. Thus, all triacylglycerols give rise to stearic acid or oleic acid or both stearic acid and oleic acid as free acids. In the absence of soap formation these free acids are reasonably well absorbed as indicated by their availabilities from OOS ( > 96\%) (Table 2). Differences in the absorption of stearic acid from OSO (>99\%) and OSS (60\%), and from

Table 2. An analysis of data from Mattson et al. (1979) on the digestibility of stearic acid (S) from triacylglycerols containing this fatty acid together with oleic acid $(\mathrm{O})$

(Mean values and standard deviations)

\begin{tabular}{|c|c|c|c|c|c|c|c|c|c|c|}
\hline \multirow[b]{2}{*}{ Triacylglycerol } & \multirow{2}{*}{$\begin{array}{l}\text { Total oleic } \\
\text { acid } \\
\text { digestibility* } \\
(\%)\end{array}$} & & \multirow{2}{*}{$\begin{array}{l}\text { Fatty acid } \\
\text { (from 1-acyl) }\end{array}$} & \multirow{2}{*}{$\begin{array}{l}\text { 2,3-diacyl- } \\
\text { glycerol'† }\end{array}$} & \multirow{2}{*}{$\begin{array}{l}\text { 1,2-diacyl- } \\
\text { glycerol† }\end{array}$} & \multirow{2}{*}{$\begin{array}{c}\text { Fatty acid } \\
\text { (from 3-acyl) }\end{array}$} & \multicolumn{2}{|c|}{$\begin{array}{c}\text { Stearic acid } \\
\text { digestibility } \\
\%\end{array}$} & \multicolumn{2}{|c|}{$\begin{array}{l}\text { Additional } \\
\text { effect of } \\
\mathrm{Ca}^{2+} \text { and } \\
\mathrm{Mg}^{2+}(\%)\end{array}$} \\
\hline & & & & & & & Mean & $\mathrm{SD}$ & Mean & SD \\
\hline $\begin{array}{l}\text { OSO } \\
\text { OOS } \\
\text { SOS } \\
\text { OSS }\end{array}$ & $\begin{array}{l}99.9 \\
99.8 \\
97.1 \\
93.5\end{array}$ & $\begin{array}{l}\longrightarrow \\
\longrightarrow \\
\longrightarrow\end{array}$ & $\begin{array}{l}\text { O§ } \\
\text { O§ } \| \\
\text { S§ } \\
\text { O§ }\end{array}$ & $\begin{array}{l}\text { - -SO }{ }^{\mathrm{a}} \S \\
-\mathrm{-OS}^{\mathrm{b}} \| \\
\text { - -OS } \\
\text { - -SS }\end{array}$ & $\begin{array}{l}\text { OS- }{ }^{a} \S \\
\text { OO- }-\S \\
\text { SO- }-{ }^{b} \\
\text { OS- }-^{a} \S \|\end{array}$ & $\begin{array}{l}\mathrm{O} \S \\
\mathrm{S} \S \\
\mathrm{S} \S \\
\mathrm{S} \S\end{array}$ & $\begin{array}{l}99 \cdot 2 \\
96.4 \\
70 \cdot 5 \\
60.1\end{array}$ & $\begin{array}{l}0.2 \\
0.3 \\
2.0 \\
2.4\end{array}$ & $\begin{array}{r}-1.9 \\
-41.4 \\
-33.5 \\
-1\end{array}$ & $\begin{array}{l}1.9 \\
1.6 \\
2.6 \\
3.1\end{array}$ \\
\hline
\end{tabular}

a,b Similar potential products in the same column.

* - -, OH group. Digestibility in the absence of additional minerals is sufficient to show that access to lipase has occurred.

$\uparrow$ As free molecules the 2,3- and 1,2-diacylglycerols are equivalent, but as enzyme-product complexes with potential to discharge the acid and the acylglycerol esters into different domains, this cannot be assumed.

* For all the stearic acid in the triacylglycerol.

$\S$ Species that can be readily digested or absorbed if not a minor route of hydrolysis.

$\|$ Products of a minor route of hydrolysis. Thus, where there is no additional effect of $\mathrm{Ca}^{2+} \mathrm{and}^{2+} \mathrm{Mg}^{2+}$, the first-cleavage product is assumed either not to yield $S$ or to yield $S$ via a minor route. 
OOS $(96.4 \%)$ and SOS $(70 \%)$ are thus due to the other first-cleavage products, which are diacylglycerols, or second-cleavage products, which are monoacylglycerols.

In the case of OSS, it appears that the first cleavage products are oleic acid and 2,3-distearoylglycerol. This is because the alternative products 1-oleoyl 2-stearoylglycerol and stearic acid do not reconcile with the remaining evidence. Thus, stearic acid production would render this reaction susceptible to soap formation and so inhibition of stearic acid absorption by the high-Ca diet, which did not occur (Table 2). Thus also, the 1-oleoyl 2-stearoylglycerol produced would probably be well digested, because it is a possible product of OSO from which oleic acid is used almost completely. Lastly, the orientation of the triacylglycerol OSS at the surface of the lipid particle is most likely to be with the 1-oleoyl group placed superior or aqueous facing and the 2,3-distearoyl grouping inferior or lipid facing, leaving lipase to digest the 1-oleoyl group and leaving 2,3-distearoylglycerol to fall back into the lipid particle or micelle from where it would be difficult to digest. Thus, the 2,3-distearoylglycerol is the species that appears difficult to digest. (Considering OSS as SSO gives the same interpretation for 1,2-distearoylglycerol as a first-cleavage product.)

In the case of SOS (Table 2), there is reduced digestion under conditions aimed at minimising soap formation, again providing evidence that one or both of the possible diacylglycerols are difficult to digest. The possible products 1-oleoyl 2-stearoylglycerol and 2-stearoyl 3oleolyglycerol (from OSO) and 2-stearoyl 3-oleoylglycerol and 1-stearoyl 2-oleoylglycerol (from SOS) differ in the positions of their stearic acid. The 2-position stearic acid in 2-stearoyl 3-oleoylglycerol and 1-oleolyl 2-stearoylglycerol probably allows the oleoyl group to be superficial at the surface of lipid particles where it may be cleaved, leaving a remnant 2stearoylglycerol to be absorbed without further cleavage. However, from SOS the products 1stearoyl 2-oleoylglycerol and 2-oleoyl 3-stearoylglycerol require stearic acid at the 1- or 3positions to be cleaved for possible stearic acid absorption, but these diacylglycerols are likely to be anchored with the stearoyl group in the lipid particle (and oleoyl group above), thus making the 3-stearoyl group or 1-stearoyl group only slowly and incompletely cleaved.

In the case of OOS there is substantial digestion of the stearic acid, implying that production of slowly-digestible 2-oleoyl 3-stearoylglycerol (or 1-stearoyl 2-oleoylglycerol from SOO) is only a minor reaction pathway; rather, the stearoyl group appears to be cleaved first, making this substrate available for soap formation, as observed (Table 2).

Where 2-oleoyl 3-stearoylglycerol (or 1-stearoyl 2-oleoylglycerol) is a potentially slowlydigestible first cleavage product, as from SOS (Table 2) it remains to be explained why stearic acid is poorly digested while oleic acid is well digested. Should cleavage not occur in the small intestine, it might occur over a longer period of time in the large intestine, with subsequent hydrogenation of some oleoyl to stearoyl. In this case the resistance of the 1- or 3-position stearoyl to digestion, although remaining substantial, would not be as great as the data in Table 2 would suggest.

It is clear that 1,2- (or 2,3-) distearoylglycerol products and 1- (or 3-) monostearoylacylglycerol products can be relatively difficult to hydrolyse, while instead being firmly anchored in the lipid matrix. From here they may concentrate and precipitate as other more digestible lipids are removed. Soap formation is an additional mechanism causing reduced digestion, but which may occur to only a relatively minor extent when there is an inadequate supply of soap-forming mineral, or when the fatty acid in the 1- or 3-position forms a lowmelting-point soap (readily absorbable), or the triacylglycerol structure yields mono- and diacylglycerols that readily anchor in the lipid matrix, or when the substrate is itself difficult to emulsify, as apparent for tristearin (Mattson et al. 1979). 


\section{Salatrim $23 C A$}

On the basis of the foregoing discussion on soaps $v$. indigestible acylglycerols, one can predict that soap formation would not be a major cause of the reduced digestion of stearic acid from Salatrim 23CA (see below and p. 197). The reason is that preferential hydrolysis of the shortchain organic acids would occur (Hayes et al. 1994a) and in two-thirds of these particular triacylglycerols this process would leave 1- (or 3-) stearoylacylglycerol and 1,2- (or 2,3-) distearoylglycerols anchored in the lipid matrix, where the stearic acid would be difficult to digest.

\section{Predicting the digestibility of other stearoyl-rich triacylglycerols}

Predictability of stearic acid absorption can be important to the assessment of nutritional claims and product safety (World Health Organization, 1999). On the basis of the observations on triacylglycerols comprising oleic and stearic acids in Table 2, discussed earlier, it would be predicted that triacylglycerols with increasing amounts of long-chain saturated fatty (e.g. stearic) acid would be more difficult to digest. This prediction was tested and affirmed by Klemann et al. (1994), who showed a linear relationship between nutritional performance in rats (energy value) of stearoyl-rich triacylglycerols and the short-chain organic acid:long-chain saturated fatty acid $(\mathrm{S}: \mathrm{L})$ molar ratio. Whereas $\mathrm{S}: \mathrm{L}$ is 1.6 in Salatrim 23CA, when it was lowered to 0.5 (as in Salatrim 4CA, amongst other experimental products), an energy value was obtained from which was calculated an apparent digestibility of only $0.2 \mathrm{~g}$ stearic acid $/ \mathrm{g}$ stearic acid intake.

Short-chain organic acid appears to be critically important. The low digestibility value for stearic acid of $0.2 \mathrm{~g} / \mathrm{g}$ in the Klemann et al. (1994) rat study, given by the product with an S:L of $0 \cdot 5$, had a triacylglycerol structure of 1,2-distearoyl 3-butyrylglycerol (SSB) + 1,3-distearoyl 2-butyrylglycerol (SBS). In comparison with tristearin in rats, of digestibility $0.15 \mathrm{~g} / \mathrm{g}$, it may be concluded that butyrate in SSB + SBS is almost as effective as stearoyl in tristearin in causing resistance of stearoyl to digestion. SSB + SBS also gave lower digestibility of stearoyl than SSO + SOS in the rat study of Mattson et al. (1979), which yielded an apparent digestibility for stearic acid of $0.65 \mathrm{~g} / \mathrm{g}$ (average of values in Table 2, without minerals). Thus, not only is the stearic acid content important but so, too, is the replacement of oleic acid by butyric acid to cause a considerable impairment in the digestion of the triacylglycerol molecule. Paradoxically, it seems, the short-chain organic acids contribute to the reduced digestibility of the stearic acid, while themselves being readily digested (Wang, 1986; Hayes et al. 1994a; DeMichelle \& Karlstad, 1995). Again, this factor points to the importance of stearoyl-rich first-cleavage products in being a cause of reduced digestion.

Such potentiation of stearic acid indigestibility by short-chain organic acids may also apply to monostearins; since in rats, SBB + BSB appears to have a stearic acid digestibility of $0.70 \mathrm{~g} / \mathrm{g}$ (Klemann et al. 1994) whereas SOO+OSO has a value of $0.97 \mathrm{~g} / \mathrm{g}$ in rats (Mattson et al. 1979). It is noteworthy that mineral soaps are often suggested as the cause of reduced stearic acid digestion; however, it is difficult to see how replacing oleic acid with butyric acid in these examples would cause additional soap formation. The simplest picture is that soap formation is unimportant in these cases, whereas a higher density of stearic acid in the triacylglycerol may be important (see Table 3). However, before considering soaps, it is valuable to consider and compare observations in human subjects and rats, as these studies show consistent findings relevant to the determinant of stearic acid digestibility. 
Table 3. Proportion of stearic acid (S) relative to total fatty acids in triacylglycerols also containing oleic acid $(\mathrm{O})$ and butyric acid $(\mathrm{B})^{*}$

\begin{tabular}{cc}
\hline Distearins & $\mathrm{g} / \mathrm{g}$ \\
SOS + SSO & 0.67 \\
SBS + SSB & 0.87 \\
Monostearins & \\
SOO + OSO & 0.33 \\
SBB + BSB & 0.62 \\
\hline
\end{tabular}

${ }^{*}$ Molecular weights of fatty acids: butyrate 88.1 , stearate $284 \cdot 5$, oleate $282 \cdot 5$.

\section{Stearoyl-density and digestion in human subjects and in rats}

Mattson (1959) suggested that it is the proportion of tristearin in triacylglycerols that determines the apparent digestibility of stearoyl-rich fats. As described earlier, the findings by Mattson et al. (1979) with structured triacylglycerols of stearic and oleic acids and that of Klemann et al. (1994) with Salatrims clearly show this proposal to be too simple. Klemann et al. (1994) considered the weight percentage of stearic acid in triacylglycerol (or stearoyldensity) as a determinant in rats, tentatively suggesting that an inflection occurred at $0.55 \mathrm{~g}$ stearic acid/g triacylglycerol, which is consistent with the need for distearoylglycerols for a low digestibility to be observed. Fig. 6 shows a similar plot, relating apparent digestibility of stearic acid to stearoyl-density, both in human subjects (using data calculated from Table 1), and in rats (using data of Mattson (1959), Mattson et al. (1979) and Klemann et al. (1994)). Fig. 6 shows that (1) there is remarkably good agreement between observations in human subjects and rats; (2) at low stearoyl density there is a fall in apparent digestibility, which can be attributed to a low stearic acid ingestion and the occurrence of endogenous excretion (as in Figs 1 and 2); in other words an artifact of the experimental circumstance rather than a property of stearoylglycerols; (3) at stearoyl density below approximately $0.45 \mathrm{~g} / \mathrm{g}$ (which is below that for any

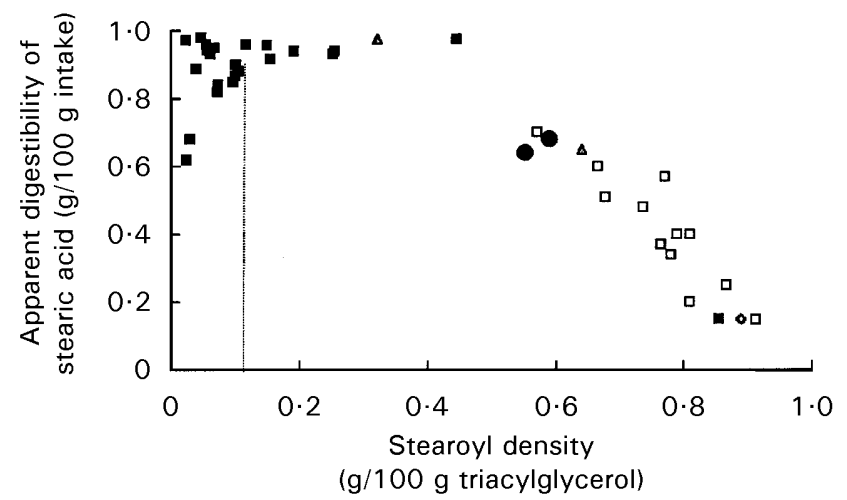

Fig. 6. Stearoyl density and apparent digestibility in human subjects and rat. Human subjects: (घ), calculated from data in Table 1; $(\bullet)$, Salatrim 23CA (a novel fat formulated with short-chain and long-chain acid triacylglycerol molecules). Rat: $(\triangle)$, triacylglycerols containing stearic acid (S) and oleic acid (O), i.e. SOO + OSO and SSO + SOS from Mattson et al. (1979), derived here from data in Table 2; $(\diamond)$, tristearin data from Mattson (1959); $\square$ ), Salatrims of various short-chain organic acid: long-chain fatty acid molar ratios from Klemann et al. (1994), ( I), density below which the apparent digestibility appears to be frequently decreased owing to endogenous excretions. 
Table 4. Molecules in Salatrim 23CA (a novel fat formulated from short-chain and long-chain acid triacylglycerol molecules) (Summarised from Softly et al. 1994)

\begin{tabular}{|c|c|c|c|}
\hline 1-position* & 2-position & 3-position & $\begin{array}{l}\text { Weight } \\
\text { (g/100 g) }\end{array}$ \\
\hline $\begin{array}{l}A \\
A \\
A \\
S \\
A\end{array}$ & $\begin{array}{l}\mathrm{A} \\
\mathrm{S} \\
\mathrm{S} \\
\mathrm{A} \\
\mathrm{Pr}\end{array}$ & $\begin{array}{l}S \\
A \\
S \\
S \\
S \\
\text { Pr }\end{array}$ & $\begin{array}{c}38.5 \\
19.2 \\
7.6 \\
3.67 \\
3.82\end{array}$ \\
\hline $\begin{array}{l}\text { A } \\
P r\end{array}$ & A & $\begin{array}{c}\mathrm{Pr} \\
\mathrm{S}\end{array}$ & 7.7 \\
\hline
\end{tabular}

of the Salatrims) stearic acid digestibility is high, whereas above this density the apparent digestibility of stearic acid falls rapidly. It may be reasoned that at stearoyl densities up to about $0.45 \mathrm{~g} / \mathrm{g}$, stearic acid can be accommodated by distribution amongst different triacylglycerol molecules, but as the stearoyl density progressively increases, further individual molecules must carry more than one stearic acid until a maximum of three is reached; (4) The point of inflection is at about $0.45 \mathrm{~g} / \mathrm{g}$ and is possibly not as sharp as these data suggest, but it is lower than $0.55 \mathrm{~g} / \mathrm{g}$, as seemed apparent from the limited analysis of Klemann et al. (1994). The identification of a lower inflection point arises in part because a larger data set is used here than before and in part because Klemann et al. (1994) considered the apparent digestibility of $\mathrm{SOO}+\mathrm{OSO}$ to be lower than that shown in Table 2. Thus one datum point on SOO + OSO fixed their point of inflection. That the inflection occurs at the lower stearoyl density indicates that monostearoyl Salatrims also contribute to low digestibility. Indeed, Salatrim 23CA includes considerable amounts of monostearoylglycerol (Table 4).

Stereoisomerism is an additional factor that remains to be explored, but is not obviously relevant in the context of randomised triacylglycerols such as Salatrims. Positional isomerism remains important; thus, SSO and SOS have the same density but different digestibilities (Table 2) with SSO $<$ SOS at low intakes of soap-forming minerals and SSO $>$ SOS at high intakes of soap-forming minerals. There are currently no data on the extent to which positional isomerism affects the hydrolysis of Salatrims. Again, this factor may not be relevant to randomised triacylglycerols.

\section{Mineral soap excretion}

The potential effects of $\mathrm{Ca}$ on the absorption of long-chain fatty acids have been extensively investigated in small animals. Although soap formation is a real mechanism causing fatty acid excretion, the nutritional importance seems to have been overemphasised with respect to the digestibility of poorly-digested triacylglycerols. For example, if soap were an important cause of reduced digestion of stearic acid from tristearin, instead of insoluble acylglycerol, we should also expect tripalmitin to show reduced absorption because calcium palmitate has long been known to be incompletely digested (Boyd et al. 1932) and high intakes of Ca elevate faecal palmitate, sometimes by as much as that found for stearate (Brink et al. 1995). However, tripalmitin is well digested and absorbed (Hoagland \& Snider, 1943; Emken, 1994). For soap excretion to be a primary cause of reduced digestibility of stearic acid from stearoyl-rich 
triacylglycerols, it would also be expected that free stearic acid would be less digestible than tristearin, which it is not (Carroll \& Richards, 1958). This expectation arises because 2monostearoylglycerol from the latter would (should digestion occur) not form soap. Further, free stearic acid elevates faecal soap excretion, whereas bound stearic acid, such as in tristearin, does not (Carroll \& Richards, 1958). Again, this finding indicates causes other than soap formation for the reduced digestibility of stearic acid from this source.

It is evident from these considerations alone that acylglycerol structure is important in conferring reduced digestibility to stearic acid in stearoyl-rich triacylglycerols. By contrast, soap formation is the major cause of excretion of oral free fatty acids. However, even when free stearic acid is fed to rats, its faecal soap with Ca accounts for only $70 \%$ of the faecal stearate (Carroll \& Richards, 1958), which again suggests a cause of reduced digestion other than soap formation. It seems possible, and open to speculation, that enzymic interesterification in vivo may even favour the conversion of some free stearic acid to acylglycerols, the direction of this reaction being made energetically favourable when the result is acylglycerols with a high melting point, such as stearoylglycerols, which might then precipitate (Small, 1991).

Ca supplements in human subjects are known to elevate fat and soap excretion, but large amounts of $\mathrm{Ca}$ are required and the effect on excretion is only modest compared with the extent of reduced stearic acid digestion from stearoyl-rich triacylglycerols. First, Drenick (1961) elevated $\mathrm{Ca}$ intake from a normal value of approximately $1 \mathrm{~g} / \mathrm{d}$ to approximately $40 \mathrm{~g} / \mathrm{d}$ using $\mathrm{CaCl}_{2}$, but this massive dose of Ca only doubled faecal fat excretion, which would cause total fat apparent digestibility to fall by approximately 5\%. Second, Denke et al. (1993) elevated Ca intake fivefold, but this decreased stearoyl digestibility by only approximately $5 \%$. Third, Mitchell et al. (1968) elevated Ca intake approximately threefold but found only a modest increase in faecal fat equivalent to $4 \%$ of fat intake. Fourth, $\mathrm{CaCO}_{3}$ at a dose of $6 \mathrm{~g}$ daily was required to double faecal fatty acid excretion in healthy men and women (Saunders et al. 1988), which corresponds to a decrease in fat digestibility of only $5 \%$. These changes in Ca intake are large compared with the normal intakes of approximately $1 \mathrm{~g} / \mathrm{d}$. It cannot be expected, therefore, that soap formation would be a significant cause of the very reduced stearic acid digestibility experienced with stearoyl-rich triacylglycerols in men and women under normal nutritional conditions (see Figs 1, 2 and 4); dietary $\mathrm{Ca}$ is just too ineffective. Stearic acid in Salatrim 23CA, being susceptible to the formation of indigestible acylglycerols, would anyway not then yield to soap formation; which is entirely consistent with results of an in vivo study from Finley et al. (1994b).

In their human study with Salatrim 23CA there was an erroneous report of high faecal Ca excretion in all the dietary groups (Finley et al. 1994c). This error in reporting gave rise to speculation that a high-Ca diet must have been fed, this despite the fact that the suggested threefold higher $\mathrm{Ca}$ intake would not have been sufficient to cause the large stearic acid excretion noted (see above paragraph). Subsequent analysis of the diet showed, nevertheless, that $\mathrm{Ca}$ intake was normal at $1.25 \mathrm{~g}$ for a human subject eating a $10 \mathrm{MJ}$ diet (J Finley, personal communication). Correct $\mathrm{Ca}$ excretion data are shown in Fig. 7, together with excretion of $\mathrm{Mg}$ (intake $450 \mathrm{mg} / 10 \mathrm{MJ}$ ) and $\mathrm{Zn}$ (intake $16 \mathrm{mg} / 10 \mathrm{MJ}$ ). For simplicity, the data in Fig. 7 are shown after pooling of data for male and female subjects (treated as blocks for the purpose of deriving the error terms). As predicted, the elevation in stearic acid excretion caused by the intake of Salatrim 23CA (Fig. 1) was not accompanied by an elevation in the excretion of Ca or other minerals (Fig. 7). This finding confirms the earlier prediction and lends weight to the view expressed here that stearic acid is poorly digested owing to properties of di- and monoacylglycerol cleavage products rather than to liberation of free acids and soap formation. 


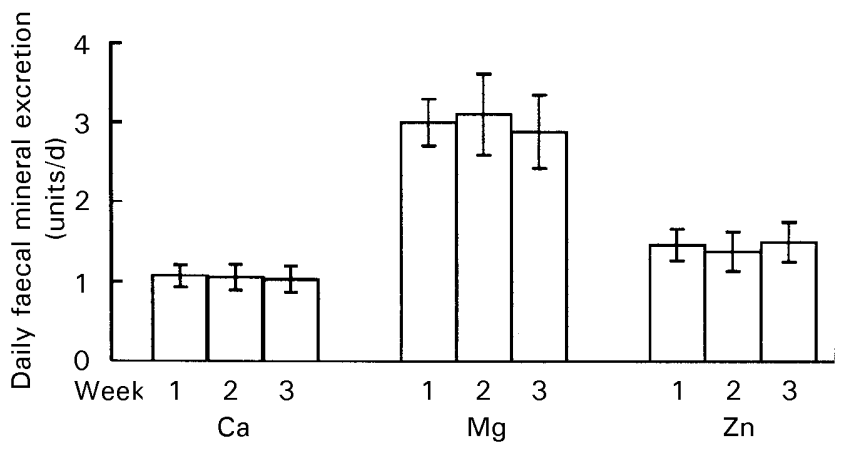

Fig. 7. Mineral excretion before, during and after consumption of Salatrim 23CA (a novel fat formulated with short- and long-chain acid triacylglycerol molecules) by adults. Data are daily excretion rates for the last $3 \mathrm{~d}$ of a $7 \mathrm{~d}$ balance period and are calculated from Finley et al. (1994b) in order to give correct units $\left(\mathrm{Ca}, \mathrm{g} / \mathrm{d} ; \mathrm{Mg}, 10^{-1} \mathrm{~g} / \mathrm{d} ; \mathrm{Zn}, 10^{-2} \mathrm{~g} / \mathrm{d}\right)$. There were no significant treatment effects. In week 2 Salatrim 23CA replaced hydrogenated coconut oil (triacylglycerols containing fatty acids 8:0, 10:0, 12:0 and 14:0) which was consumed before (week 1) and after (week 3 ) this period. Values are means with their standard errors represented by vertical bars.

\section{Dose response of stearic acid digestibility from triacylglycerols}

At present, no studies have shown dose dependency in the digestion of stearic acid from triacylglycerols in favour of a decreasing digestion with increasing dose. Thus, the digestive tract must have a remarkable capacity to digest triacylglycerols and absorb stearic acid from those tristearoylacylglycerols that are digestible to yield absorbable stearic acid. Studies on dose response are now discussed.

First, the true digestibility of stearic acid from traditional fats in human subjects remains unchanged with increasing stearic acid intake (with apparent digestibility rising owing to endogenous excretion; Figs $1 \& 2$ ). Thus, up to $47 \mathrm{~g}$ stearic acid/d from triacylglycerol can be absorbed, and there is no evidence in Fig. 1 of a limit to absorption being approached.

Second, Hoagland \& Snider (1943) were among the first researchers to provide data that address the question of dose dependency. They investigated the effect of triolein and tripalmitin on the digestibility of tristearin in the presence of $>90 \%$ excess olive oil (predominantly triolein, 1,2-dioleoyl 3-palmitoylglycerol and 1,2-dioleoyl 3-linoleoylglycerol; Small, 1991). Although dose dependency of stearic acid digestion was not a question for these authors (who were, instead, concerned about interactions between homotriacylglycerol mixtures), the absence of effect of tripalmitin and triolein resulted in a study that provides information on tristearin digestibility at different doses given to rats at $0,2.5,5$ and $10 \%$ of a constant fat intake $(5 \mathrm{~g} / 100 \mathrm{~g}$ diet $)$. The results of their study are presented here in a form suggested by Livesey (1990) for the assessment of partial digestibility for a two-component mixture (tristearin and other fats; Fig. 8). The straight line that results from regression analysis is $\mathrm{Y}=97$ (SE 0.2) $-0.82(\mathrm{SE} 0.03) \mathrm{X}$, where $\mathrm{Y}$ is apparent digestibility of the whole tristearin-fat mixture and $\mathrm{X}$ is the weight proportion of fat that is tristearin. From these data, the partial digestibility of the tristearin is 15 (SE 17) g/100g ( $\mathrm{Y}$ when $\mathrm{X}=100$ ) and is essentially independent of dose.

Third, Mattil \& Higgins (1945) provided triolein and tristearin mixtures to rats in ratios of 2:1 and 1:2 with resulting digestibilities of 69 and $39 \mathrm{~g}$ fat $/ 100 \mathrm{~g}$ fat intake respectively. These 


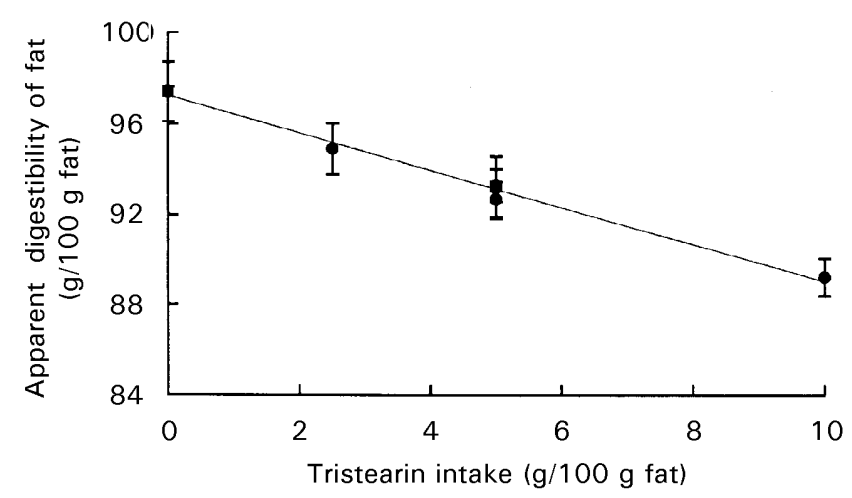

Fig. 8. Apparent digestibility of fat in rats fed tristearin in olive oil. Values are means and standard deviations represented by vertical bars. The regression line has an intercept of 97.2 (SE $0.2) \mathrm{g} / 100 \mathrm{~g}$ fat and a slope of -0.82 (SE 0.03 ) $\mathrm{g} / 100 \mathrm{~g}$ fat, corresponding to a partial digestibility of tristearin of 15 (SEM 17) $\mathrm{g} / 100 \mathrm{~g}$ tristearin. (Data from Hoagland \& Snider, 1943.)

data suggest no interaction between tristearin and triolein and partial digestibilities for triolein and tristearin of 99 and $9 \mathrm{~g} / 100 \mathrm{~g}$ fat respectively but no dose dependency of tristearin digestion.

Fourth, Mattson (1959) also showed in rats that increasing the tristearin content of a mix with triolein (total fat $15 \mathrm{~g} / 100 \mathrm{~g}$ diet) caused a linear decrease in the apparent digestibility of stearic acid, thus confirming that dose is not a factor.

Fifth, Finley et al. (1994a) reported that Salatrim (23SO; M. Auerbach, personal communication), prepared from triacetin $\left(\mathrm{C}_{2}\right.$ acid), tripropionin $\left(\mathrm{C}_{3}\right.$ acid) and hydrogenated soyabean oil and of low S:L molar ratio (1.3) fed to rats at 5, 10 and $15 \mathrm{~g} / 100 \mathrm{~g}$ diet gave results from which this author calculates true digestibilities for its stearic acid to be 36,39 and $35 \mathrm{~g} /$ $100 \mathrm{~g}$ stearic acid intake, again a result independent of dose.

Sixth, the digestibility of stearic acid from cocoa butter in rats also remained unchanged at doses from 5 to $10 \mathrm{~g} / 100 \mathrm{~g}$ diet, whereas it was increased at doses from 10 to $20 \mathrm{~g} / 100 \mathrm{~g}$ diet (Apgar et al. 1987).

\section{Mixtures of stearoyl-rich triacylglycerols with other fats}

Up to $30 \mathrm{~g}$ endogenous fat may enter the human intestine every $24 \mathrm{~h}$ (Cotton, 1972). Mixing in vivo of either tristearin or Salatrim with endogenous fat appears to be insufficient to release stearic acid readily from these stearoyl-rich fats. The co-ingestion of olive oil with tristearin does not facilitate stearoyl digestion in the rat (Hoagland \& Snider, 1943); in human subjects, the co-ingestion of a simple mix of triolein, trilinolein and trilinolenin with tristearin leaves the stearic acid of tristearin poorly absorbable (Emken, 1994). It is plausible, however, that the particular forms in which fat mixtures with stearoyl-rich triacylglycerols are presented in the diet (such as crystalline, melt or emulsion) may affect the extent of digestion. The forms in which manufactured Salatrim 23CA (see Figs. 1 and 2) and tristearin have been presented, clearly leave them with substantially reduced stearoyl digestibility. Thus, the emulsifying capability within the rat (Mattson, 1959; Finley et al. 1994a), dog (Arnschink, 1890) or human (Hashim \& Babayan, 1978; Finley et al. 1994b) digestive tract (should this factor be limiting), is not sufficient to cause stearic acid to be yielded readily to absorption. 
Pre vivo emulsification and dissolution with triacylglycerol mixtures

Experimental designs on the digestibility of stearoyl-rich triacylglycerols fall into at least three categories according to the following digestion schemes:

$$
\text { Intake ... emulsification ... digestion ... }
$$

Homogenisation or emulsification ... intake ... further emulsification ... digestion ...

$$
\text { Dissolution ... intake ... emulsification ... digestion ... }
$$

The earlier discussion has concerned (in the main) scheme 1, which represents events under normal eating circumstances. The studies described have shown that the digestive tract is not capable of adequately emulsifying stearoyl-rich triacylglycerols such as tristearin and Salatrims, as prepared, with adequate vigour to make their stearic acid readily available. However, under certain conditions it appears possible to facilitate digestion of tristearin by processing pre vivo.

Homogenisation or emulsification pre vivo of tristearin as the lone fat, in the presence of sucrose and protein, also appears to leave stearoyl digestibility very low, both in human subjects (Hashim \& Babayan, 1978) and in rats (Bergstedt et al. 1990, 1991). Likewise, a mixture of tristearin with triolein, trilinolein and trilinolenin shows reduced digestion and appearance of stearic acid in plasma in human subjects when the mixture is processed pre vivo by homogenisation with sugar, casein and water at $70^{\circ} \mathrm{C}$ (Emken, 1994). Thus scheme 2 also appears to be insufficient to make stearic acid from tristearin readily available.

Digestion of stearic acid from tristearin appears to be increased by progressively increasing the temperature at which tristearin is homogenised with sucrose and protein, from 70 to $80^{\circ} \mathrm{C}$, in the presence of a mixture of triolein, trilinolein and trilinolenin (Emken, 1994). Similarly, Hashim \& Babayan (1978) showed a homogenate of tristearin with sucrose, protein and maize oil (major triacylglycerols: trilinolein, 1,3-dilinoleoyl 2-oleoylglycerol and 1,2-dilinoleoyl 3palmitoylglycerol; Small, 1991) at $80^{\circ} \mathrm{C}$ to halve stearic acid excretion to human stools from ingested tristearin. It is probably significant that tristearin has a melting point of $73^{\circ} \mathrm{C}$ (Small, 1991), which was traversed by the processing in these studies. Such conditions are likely to have given a solution of tristearin in other oils, in which solid crystal structures would obviously be disrupted. Scheme 3 thus results in an improved digestion of stearic acid from tristearin, but is conditional on the temperature at which the tristearin is diluted with other fats.

Animal studies appear to complement these studies in human subjects. The appearance of stearic acid in lymph following an oral emulsion of tristearin was low in rats, but was improved by including either tripalmitin or triolein in the emulsion prepared by sonication with phosphatidylcholine and sodium taurocholate (Bergstedt et al. 1991). This vigorous process may also be presumed to disrupt solid crystal structures and to facilitate dissolution of the tristearin in the other oils.

Thus, whereas early studies showed that non-emulsified and non-solubilised mixtures of triacylglycerols had low stearic acid digestion (Hoagland \& Snider, 1943; Mattil \& Higgins, 1945; Mattson, 1959), pre vivo emulsification or solution in oils show improved stearic acid digestion from tristearin (Hashim \& Babayan, 1978; Bergstedt et al. 1991; Emken 1994). The significance of such pre vivo solubilisation and emulsification when the digestive tract is not capable of reproducing this process is doubtful from a physiological perspective, and indicates that care should be taken to distinguish between food processing on the one hand and physiological events on the other. Such a processing effect also potentially has implications for interpretation of some studies on randomisation. Thus, when fed as part of a liquid diet 
(Bonanome \& Grundy, 1988) a near-complete digestion of stearic acid was observed from a randomised mixture of hydrogenated soyabean oil and safflower oil. Before randomisation the triacylglycerol molecules in the mixture were triolein, OSO and OSS, and afterwards they would be randomisation products. The procedure for randomisation is equivalent to solubilising the high-melting-point stearoylglycerol (OSS) in lower-melting-point oils (triolein and OSO), a procedure that is equivalent to scheme 3 . Thus, the randomisation procedure will dissolve highmelting-point fats to cause improved digestion, even if randomisation otherwise has no effect. One can predict, however, that in this case the randomisation would also yield highly-digestible triacylglycerol molecules by losing OSS.

\section{Molecular and microcrystalline resistance to digestion}

A role for microcrystalline structures in the resistance to digestion of stearoyl triacyglycerols has been suggested previously. For tristearin (melting point $73^{\circ} \mathrm{C}$ ) it is difficult in any published study to distinguish between two causes of reduced digestion, i.e. inaccessibility of enteric lipases to the substrate due to its microcrystallinity, and reduced hydrolysis due to molecular structure of the triacylglycerol accessed by lipase. There are, however, sufficient data to argue that both have a role. With the structured lipids SOO, OSS and SOS (Table 2), the highest melting point of any one of them is $42^{\circ} \mathrm{C}$ (Small, 1991) and so no reason exists in these cases to expect reduced access of lipases due to a crystalline matrix. The virtually complete absorption of the oleic acid from these molecules indicates that the triacylglycerols were indeed accessed by lipases, so that within the time course of the digestion process all molecules of triacylglycerol had been accessed. Similar criteria can be applied to Salatrim 23CA.

Although for Salatrims there is no direct determination of apparent digestibility of the short-chain groups, studies in rats show that these groups, when ${ }^{14} \mathrm{C}$-labelled, give rise to ${ }^{14} \mathrm{CO}_{2}$ production very early after introduction into the stomach of rats by intubation. The short-chain groups were removed early during intestinal digestion, and approached completion (Hayes et al. 1994a); thus, reduced digestion of the stearic acid from Salatrim 23CA is not the result of impeded access of lipases. Moreover, although Salatrims are partly microcrystalline at room temperature (Narine \& Marangoni, 1999a,b), such microcrystals will have no role in preventing digestion, because the melting point of Salatrim 23CA and various other Salatrim preparations is in the range $31-35^{\circ} \mathrm{C}$ (with the exception of one of the family that is hardened with $7 \%$ added tristearin; $\mathrm{M}$ Auerbach, personal communication). Such melting points are both below body temperature $\left(37^{\circ} \mathrm{C}\right.$ ) and well below $50^{\circ} \mathrm{C}$, the critical temperature above which the melting point of a fat is thought to hinder digestion (Cockett \& Deuel, 1947; Cheng et al. 1949). An implication is that blending Salatrim with low-melting-point oils is not expected to improve access of lipases to this triacylglycerol. Recent studies in the rat showed that Salatrim in such blends still had low digestibility (KC Hayes, personal communication). Salatrims are, anyway, tailored to have desirable functionalities for food processing without the need for blending.

\section{Regulatory aspects of fat digestion}

The results of many types of experiments need not always be precise in order for conclusions to be drawn, with observations relative to controls often being sufficient. For regulatory purposes, the results of practical work should be as close to absolute as is reasonably possible because, for practical purposes, comparisons are made between results of different experiments (determinations, which may be on different products), and between experimental observations (on a 
product) and boundaries that are deemed to define what is or is not an energy or fat reduction. For example, a small error in fat or energy value determination can allow or disallow a fat or food containing the fat from a claim to being 'reduced fat' or 'reduced energy' (for example, see Codex Alimentarius, 1991). However, to date, food regulations have not been able to take account of variation in availability of components between individuals, and so determinations require adequate numbers of subjects to ensure that the results are representative of the population. These points are clearly of practical rather than nutritional significance, but emphasise the need for care over experimental and analytical methods. In addition, the definition of fat in foods is under revision for novel foods, and calculations of energy value are a source of potential difficulty.

\section{Definition of intake}

It is usual to consider a nutritional value as applying to a typical intake. For novel foods, this value cannot be the average intake for the population, as with regular foods. Estimates of population average intakes are always much less than typical intakes for a novel food (Ministry of Agriculture, Fisheries and Foods, 1990). Nutritional value applicable to a regular portion size or higher for consumers of major amounts is more relevant and this value also needs to be representative of the eating occasion, particularly for substrates digested in the upper intestinal tract. Eating a novel fat in portions of $15 \mathrm{~g}$ three times daily may be representative of a typical intake per eating occasion, whereas $45 \mathrm{~g}$ once daily would not be likely to be so, yet both represent a daily intake of $45 \mathrm{~g} / \mathrm{d}$. As a single dose, this intake would probably be unrepresentative. Published studies on fat digestibility usually state the daily fat intake, but it is uncommon to publish information about the distribution between meals. In the case of the very high stearic acid excretion from Salatrim 23CA (Fig. 1), and low apparent digestibility (Fig. 2), intakes were spread between three meals corresponding to $15 \mathrm{~g}$ per meal (females) or four meals (males) to represent intakes per eating occasion (Finley et al. 1994b).

\section{Kinetics of excretion of indigestible substrates}

A factor often overlooked in experimental design is the time course for the loss of indigestible matter to faeces and the irregularity of mixing and excretion of the digestive and faecal stream. This problem is common to many (but not all) fat-balance studies (Bonanome \& Grundy, 1988; Denke \& Grundy, 1991), and occurs when indigestible markers are not presented at every meal (Lentner et al. 1975). Indigestible markers allow the kinetics of appearance of indigestible material in faeces to be determined, thus avoiding an underreporting of indigestible fat excretion, as exemplified with an indigestible marker in Fig. 9 for two females with atypically long transit times $(5 \mathrm{~d}$ lag) through the digestive tract. For these two females, a $7 \mathrm{~d}$ balance with a $3 \mathrm{~d}$ faecal collection would have resulted in an underrecovery of indigestible markers by $60 \%$, compared with expected recovery in the steady-state that was eventually reached. For balance studies that have a pre-feeding period sufficiently long for a steady-state to have been reached, the use of indigestible markers also prevents overestimation of digestibility due to episodic and temporal retention of excreta in the colon during usually the latter half of the balance period (holdover), or underestimation when holdover occurs late in the immediate pre-balance period. The use of indigestible markers allows the variation in the estimate of digestibility on this account to be reduced, in addition to allowing a more accurate mean digestibility value to be determined. 


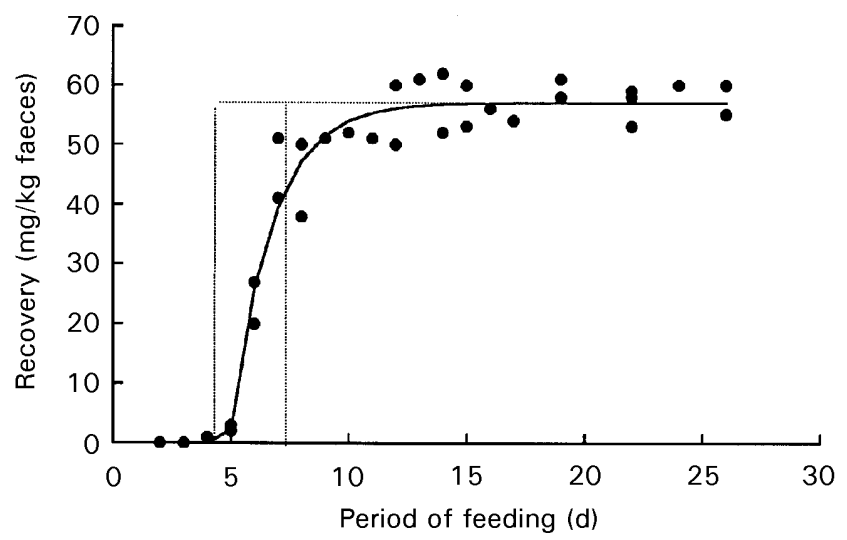

Fig. 9. Recovery of an indigestible marker, chromic sesquioxide, from two human subjects with long transit times for passage through the intestine. Daily faecal-marker recovery data from Sharpe \& Robinson (1970) were fitted to a lag-rising exponential of the general form $y=C-k e^{-b(t-a)}$ with the resultant curve shown. This procedure allowed the area above the curve bound by the rectangle placed across days 5,6 and 7 to be quantified. In these extreme cases the recovery for a $7-d$ balance study with collection during the last $3 \mathrm{~d}$ (see also the study of Finley et al. 1994b) was only $40 \%$ of the steady-state rate. For more normal transit times based on additional data from Cummings \& Wiggins (1976) on plastic pellets, by Davignon et al. (1968) on chromic oxide, and by Allen et al. (1979) on polyethylene glycol recovery was 66 (SE 15)\%. Where the transit is speeded by $2 \mathrm{~d}$, as it may be owing to the consumption of indigestible substances, the recovery would have been 89 (SE 10)\%.

As an example, consider the experimental work of Finley et al. (1994b), which was well conducted but had no such faecal markers. Based on the kinetics typical of several other studies (Davignon et al. 1968; Cummings \& Wiggins, 1976; Allen et al. 1979), the experimental design employed is expected to have underestimated faecal stearic acid from Salatrim 23CA by $11 \%$, even after assuming that Salatrim decreases the average transit time by $2 \mathrm{~d}$ owing to its bulking characteristics. A further source of error in this particular study is holdover in at least one female subject during the $3 \mathrm{~d}$ balance period, as judged from a very low faecal $\mathrm{N}$ excretion. This factor would have caused a further overestimation in the digestibility of the stearic acid from this fat, and partly explains the higher stearic acid digestibility from Salatrim 23CA reported in female subjects than in male subjects (Finley et al. 1994b). A further possible explanation for this male-female difference is that it is partly an artifact of different intestinal transit times, which tend to be longer in females, who are frequently more constipated than males (Koizumi et al. 1983). Had a longer pre-feeding period been used to ensure that a steadystate had been reached, or had indigestible markers been used to correct for this factor, it is possible that no male-female difference in stearic acid digestibility from Salatrim 23CA would have been found.

\section{Implications of analytical methods for stearic acid analysis}

The method used to analyse stearic acid (and other fatty acids and fats) in faeces is often judged to be important, yet authors often give too little information to allow their study to be reproduced, and some reports even refer to apparently unpublished methods so that details are not necessarily available (Dougherty et al. 1995). The most common method is the analysis of 
solvent-extractable fat, with or without either previous acid or alkaline hydrolysis, together with an analysis of fatty acids as a proportion of total fatty acids (for example, see Olubajo et al. 1986; Mitchell et al. 1989; Finley et al. 1994b). This method is generally satisfactory when total faecal fats are mainly fatty acids alone, but this is seldom the case unless there is substantial intake of indigestible triacylglycerol. Errors of $10-20 \%$ of the total faecal fat might be expected due to co-extraction of extraneous matter with the faecal fat. Denke \& Grundy (1991) claim that, under some circumstances, this procedure (when involving saponification) may overestimate fatty acid excretion twofold. These authors recommend an interesterification procedure together with the use of a marker (17:0) of fatty acid recovery (Bonanome \& Grundy, 1988; Denke \& Grundy, 1991). On the other hand, underestimation of faecal fats may occur owing to the use of lipid extractants, such as light petroleum (b.p. $40-60^{\circ} \mathrm{C}$ ), that omit any polarity, should appropriate precautions not be taken (DJ Baer, JT Judd, PM Kris-Etherton, $\mathrm{G}$ Zhao and EW Emken, unpublished results). Those interested in the digestion of triacylglycerols should seek to extract fatty acids from both neutral and soap fats. Experimental design and calculations, as well as improved analytical methods, may overcome some of this problem.

The problems of extraction of extraneous matter with faecal fat can, in principle, be overcome within an experimental design, by estimating the change in faecal fat or stearic acid due to changes in triacylglycerol intake, where such extraneous material is likely to be similar on each diet and so nullified by the difference calculation (difference in fat excretion due to change of fat in the diet). It is important to note, however, that this estimation is seldom done, even when it is essential to obtain a digestibility value for the test fat or fatty acid; more often, the digestibility of a fat or fatty acid in the whole diet is reported. The addition of a fat of low digestibility to a diet including readily-digestible fat will yield an overall fat digestibility intermediate between the two; that is, higher than that for the less-digestible test fat due to averaging. Thus, for example, the study by Finley et al. (1994b) slightly overestimated the digestibility of stearic acid from Salatrim 23CA, by about $2 \%$ as those authors assumed that it would be the same as that for the diet as a whole.

\section{The nutritional value as fats of stearoyl-rich fats}

In consideration of the non-nutritional value of fat lost to faeces, the USA has listed specific digestibility coefficients for fats in different categories (or food classes) in their food tables (see Merrill \& Watt, 1973). The Food and Drug Administration (1996) has proposed that this consideration also may be applied to fats of low digestibility for the purpose of nutrition labelling of fat in foodstuffs. Triacylglycerols that comprise stearic acid generally contain other long-chain fatty acids, so that the apparent digestibility of the whole triacylglycerol provides a conversion factor for the derivation of available fat. Such fat availability values are shown in Table 5 for cocoa butter and tristearin. Owing to its high palmitic and oleic acid content, cocoa butter fat has a high availability $(0.93 \mathrm{~g} / \mathrm{g})$ whereas, owing to the high stearic acid content of tristearin, its availability as fat is low for the product as prepared. The situation with Salatrim 23CA differs from that of cocoa butter and tristearin because only $61 \mathrm{~g} / 100 \mathrm{~g}$ Salatrim 23CA is potentially available as long-chain fat; the remainder is short-chain organic acids and glycerol backbone associated with these short-chain acids. The known loss to faeces of stearic acid is $22 \cdot 1 \mathrm{~g} / 100 \mathrm{~g}$ Salatrim 23CA ingested (Finley et al. 1994a). In addition, there are 'other fats' lost to faeces associated with ingestion of this Salatrim (Fig. 10), which amounted to $5.6 \mathrm{~g} / 100 \mathrm{~g}$ Salatrim 23CA ingested. This factor brings the overall availability of Salatrim 23CA as fat to $33 \mathrm{~g} / 100 \mathrm{~g}$ (Table 5). 
Table 5. Available fat and energy values of selected stearoyl-rich fats

\begin{tabular}{|c|c|c|c|}
\hline & Cocoa butter & Salatrim $23 C A$ & Tristearin \\
\hline $\begin{array}{l}\text { Major triacylglycerols (showing } \\
\text { the acyl groups in the } \\
1-, 2-\text { and 3-positions respectively) }\end{array}$ & $\begin{array}{l}\text { POS }^{*} \\
\text { SOS }^{*} \\
\text { POP }^{*}\end{array}$ & $\begin{array}{l}\text { AAS } \dagger \\
\text { ASA } \dagger \\
\text { ASS } \dagger\end{array}$ & SSS \\
\hline Gross fat content & 1 & $0.61 t$ & 1 \\
\hline Stearic acid content ( $\mathrm{g} / \mathrm{g}$ product) & $0.35 \S$ & $0.53 \|$ & $0.95(0.86)$ \\
\hline Stearic acid digestibility (g/g stearic acid) & $0.95^{\star \star}$ & $0.58+\dagger$ & $0.15+t$ \\
\hline Available fat ( $\mathrm{g} / \mathrm{g}$ product) & $0.93 \S \S$ & 0.33\|\| & $0.15+$ \\
\hline Energy value: $\mathrm{kJ} / \mathrm{g}$ & 36.5 ฯ & $20 \cdot$ & $6 \uparrow$ \\
\hline $\mathrm{kcal} / \mathrm{g}$ & $8 \cdot 7^{\star \star \star}$ & 5 & 1.5 \\
\hline
\end{tabular}

A, acetyl; O, oleoyl; P, palmitoyl; S, stearoyl.

* From Small (1991).

$\dagger$ From Softly et al. (1994); see Table 3.

Excludes short-chain fats and associated glycerol.

$\S$ Mitchell et al. (1989).

$\|$ As derived herein, given (Finley et al. 1994a) that stearic acid comprises $0.57 \mathrm{~g} / \mathrm{g}$ fatty acids.

- For 0.95 , the remainder is glycerol; the value in parentheses refers to the material investigated (see footnote $\$$ ).

$\star *$ Digestibility of stearic acid reported by Mitchell et al. (1989) was 0.39 , but is inconsistent with fat balance data and triacylglycerol composition and structure. From Shahkhalili et al. (2000) the digestibility of stearic acid from cocoa butter is $0.95 \mathrm{~g} / \mathrm{g}$ stearic acid.

$\dagger$ After corrections for basal diet and kinetics of excretion of indigestible matter.

\$t Unblended high tristearin; from Hashim \& Babayan (1978); stearate:palmitate 9:1, adjusted for assumed kinetics of faecal loss (Hoagland \& Snider, 1943; Emken, 1994).

$\S \S$ From Mitchell et al. (1989), Denke \& Grundy (1991), Langworth \& Holmes (1917) and Shahkhalili et al. (2000).

\|\| As derived herein (low value due to low energy from short-chain organic acids).

- Available fat $x$ heat of combustion.

$\star \star \star 1 \mathrm{~kJ}=4.184 \mathrm{kcal}$.

The nature of the 'other fats' in faeces after Salatrim 23CA ingestion requires some comment. Of the 5.6 g/100 g Salatrim 23CA ingested that appeared in faeces (Fig. 10 and Table 6), some will be glycerol associated with the excreted stearic acid (as in small animals; Hayes et al. 1994a) and some will be long-chain fatty acids other than stearic acid from Salatrim 23CA that are also poorly absorbed, such as lignoceric, behenic and palmitic acids, of which there are small amounts (Finley et al. 1994a,b). Note that although palmitic acid is better

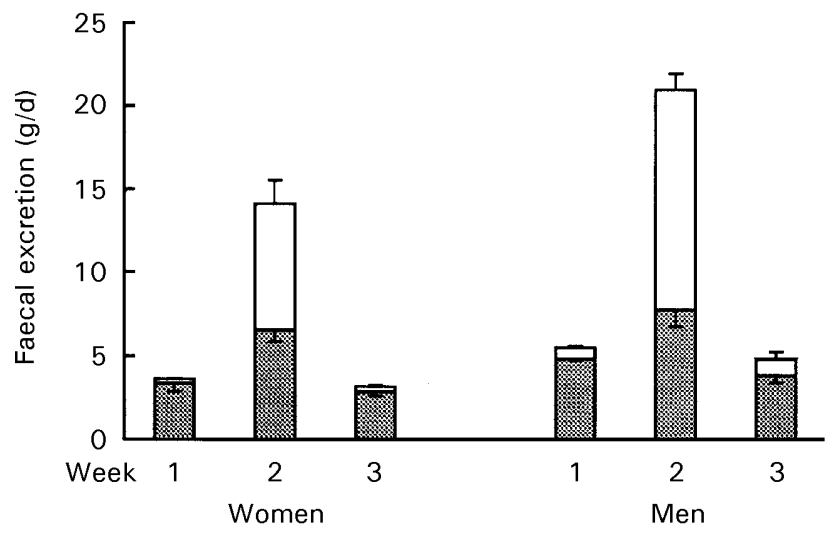

Fig. 10. Effect of Salatrim 23CA (a novel fat formulated with short- and long-chain acid triacylglycerol molecules) on faecal fat other than stearic acid. Original data for individual subjects from the study of Finley et al. (1994b) were analysed before (week 1), during (week 2) and after (week 3) a 1-week replacement of hydrogenated coconut oil with Salatrim 23CA (three $15 \mathrm{~g}$ portions daily in women $(n 4)$ and four $15 \mathrm{~g}$ portions daily in men $(n 12))$. Data are group means with their standard errors represented by vertical bars for stearic acid ( $\square$ ) and 'other fat' calculated as total fat less stearic acid $(\square)$ after two-way analysis of contrasts (subject and treatment). Salatrim treatment effect on 'other fat' was significant $(P<0.01)$ for both men and women. 
Table 6. Availability of fat from Salatrim 23CA (a novel fat formulated from short-chain and long-chain acid triacylglycerol molecules; g/100 g Salatrim)

(Values are means with their standard errors)

\begin{tabular}{lcc}
\hline & Mean & SEM \\
\hline Potentially available fat from Salatrim & 61.0 & - \\
Unavailable from stearic acid & 22.1 & 1.0 \\
Unavailable from 'other' fats found excreted & 5.6 & 1.1 \\
Potentially from glycerol of stearate & 1.10 & 0.05 \\
Potentially other Salatrim fat & 1.79 & 0.08 \\
Unaccounted fat in faeces & $2.3^{*}$ & 1.1 \\
Available fat & 33.3 & 1.5 \\
\hline Mean value was significantly different from zero $(n 17, t$ test for \\
$\mu=0):{ }^{\star} P<0.05$.
\end{tabular}

digested than stearic acid (Fig. 4), wherever stearic acid is poorly digested so, too, is palmitic acid. Thus, a reduced digestion of palmitic acid occurs in infants in association with reduced stearic acid digestion (Fig. 5) and a reduced digestion of stearoylglycerols causes palmitic acid in the same triacylglycerol to be equally poorly digested (as may be calculated from the studies of Hashim \& Babayan, 1978). After accounting for these fatty acids, the remaining faecal fat to be accounted for was significant $(P<0.05)$, but almost negligible in amount, at $2.3 \mathrm{~g} / 100 \mathrm{~g}$ Salatrim 23CA (Table 6).

Contributing to these remaining fatty acids may be the products of microbially-mediated hydroxylation to hydroxystearic and other acids, the former of which may normally account for $13 \%$ of the total faecal fatty acids (Henry, 1964). Additionally, acylglycerol intermediates may inhibit the digestion of other fats, or faecal bulking may occur in association with a shorter transit time, as occurs after elevation of dietary fibre intake (Baer et al. 1997). The elevation of faecal fat after Salatrim 23CA ingestion is not all attributable to stearic acid (Fig 10, Table 6), and is accompanied by an elevation in protein $(\mathrm{N} \times 6.25)$ excretion (Fig. 11), indicating that these effects are probably due to a shorter intestinal transit time to cope with the bulk.

\section{The energy values of stearoyl-rich fats}

Again, Salatrim 23CA is the only stearoyl-rich fat for which the energy value for nutrition labelling purposes has been estimated extensively, in both men and women and on several occasions in animals (Finley, 1994a,b; Hayes et al. 1994a; Klemann et al. 1994). This situation contrasts with the paucity of the observations often used for foods in studies collated by Merrill \& Watt (1973) for the purpose of establishing specific energy factors for food tables in the USA, and is far more than was done by Atwater \& Bryant (1900) when the food energy evaluation system was first devised. An energy evaluation exists also for tristearin in rats (Ranhotra et al. 1998), but there are only few adequate and directly determined data for human subjects and these are based on observations for one male subject (Hashim \& Babayan, 1978), although this information is supported by plasma appearance values from human (Emken, 1994) and animal studies (Mattson, 1959). Much more information is available for cocoa butter in male subjects (Langworth \& Holmes, 1917; Mitchell et al. 1989; Denke \& Grundy, 1991; Shahkhalili et al. 2000) and in rats (Apgar et al. 1987). The energy values given in Table 5 for all three stearoylrich fats (cocoa butter, Salatrim 23CA and tristearin) are derived from these data.

An energy value of $20 \mathrm{~kJ}(5 \mathrm{kcal}) / \mathrm{g}$ has been estimated for Salatrim 23CA (Table 7), as derived by Finley et al. $(1994 a, b)$, but there are important differences in the approach. The 


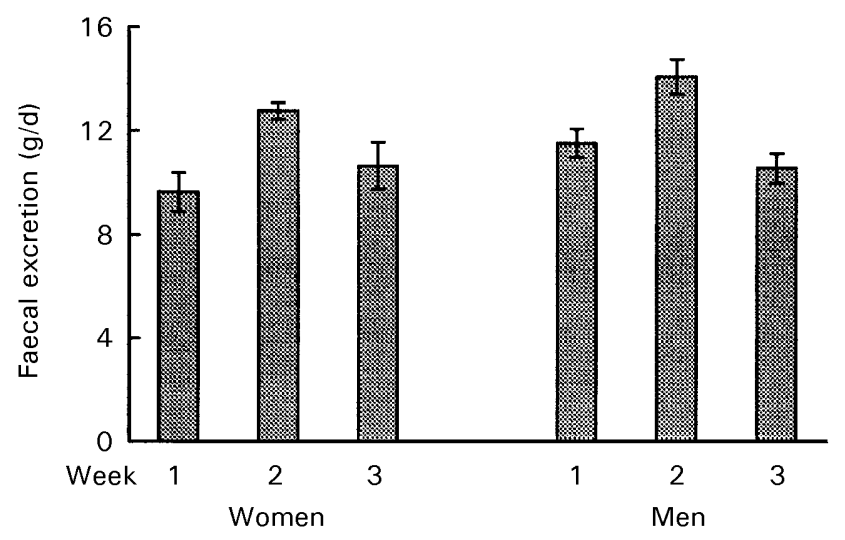

Fig. 11. Effect of Salatrim 23CA (a novel fat formulated with short- and long-chain triacylglycerol molecule) on faecal protein (nitrogen $\times 6 \cdot 25$ ). Original data on individual subjects from the study of Finley et al. (1994b) were analysed before (week 1), during (week 2) and after (week 3) a 1week replacement of hydrogenated coconut oil with Salatrim 23CA, three $15 \mathrm{~g}$ portions daily in women $(n 4)$ and four $15 \mathrm{~g}$ portions daily in men $(n 12)$. Data are group means with their standard errors represented by vertical bars after two-way ANOVA. The Salatrim treatment effect was significant for women $(P<0.05)$ and for men $(P<0.01)$ (two-way analysis of contrasts).

Table 7. Influence of sources of bias on the energy values of Salatrim 23CA (a novel fat formulated from shortchain and long-chain acid triacylglycerol molecules)

(Values are means with their standard errors)

\begin{tabular}{|c|c|c|c|c|c|}
\hline & $n$ & Mean & SEM & Mean & SEM \\
\hline Digestibility of stearic acid & & & & \multicolumn{2}{|c|}{ (g/g ingested) } \\
\hline $\begin{array}{l}\text { Men, uninspected data, whole diet, as measured } \\
\text { Women, uninspected data, whole diet, as measured } \\
\text { Average of the male and female uninspected means } \\
\text { Weighted average of uninspected data (male=female) } \\
\text { Weighted average after one impossible result removed } \dagger \\
\text { Stearic acid from Salatrim, łunadjusted for loss kinetics } \\
\text { Stearic acid from Salatrim, ładjusted for loss kinetics§ }\end{array}$ & $\begin{array}{r}12 \\
5 \\
17 \\
17 \\
16 \\
16 \\
16\end{array}$ & & & $\begin{array}{l}0.630 \\
0.720 \\
0.680 \\
0.661 \\
0.646 \\
0.619 \\
0.583\end{array}$ & $\begin{array}{l}0.030 \\
0.050 \\
0.040 \\
0.026 \\
0.022 \\
0.023 \\
0.024\end{array}$ \\
\hline Digestible energy value & & \multicolumn{2}{|c|}{$(\mathrm{kJ} / \mathrm{g})$} & \multicolumn{2}{|c|}{$(\mathrm{kcal} / \mathrm{g})$} \\
\hline $\begin{array}{l}\text { Computed as suggested in previous publications } \| \\
\text { Computed without (inappropriate) heat of formation of water } \\
\text { After adjustment for total fat excretion } \\
\text { After adjustment for protein excretion } \dagger \dagger\end{array}$ & $\begin{array}{l}16 \\
16 \\
16 \\
16\end{array}$ & $\begin{array}{l}21 \cdot 7 \\
23 \cdot 1 \\
22 \cdot 6 \\
21 \cdot 2\end{array}$ & $\begin{array}{l}0.6 \\
0.6 \\
0.8 \\
1.0\end{array}$ & $\begin{array}{l}5 \cdot 19 \\
5.51 \\
5 \cdot 18 \\
4 \cdot 84\end{array}$ & $\begin{array}{l}0.14 \\
0.14 \\
0.19 \\
0.23\end{array}$ \\
\hline Vet metabolisable energy & & & & & \\
\hline $\begin{array}{l}\text { Before adjustment for protein excretion } \\
\text { After adjustment for protein excretion }\end{array}$ & $\begin{array}{l}16 \\
16\end{array}$ & $\begin{array}{l}20.0 \\
18.5\end{array}$ & $\begin{array}{l}1.0 \\
1.0\end{array}$ & $\begin{array}{l}4.78 \\
4.42\end{array}$ & $\begin{array}{l}0.20 \\
0.23\end{array}$ \\
\hline
\end{tabular}

* Results for one subject (subject 212, a female, see Finley et al. 1994b) yielded a net metabolisable energy value greater than the heat of combustion of the Salatrim, which was attributed to faecal retention.

$\dagger$ Impossible result for subject 212 removed.

$\$$ Dietary data give too high a value for the stearic acid digestibility from Salatrim, due to high digestibility of stearic acid in the basal portion of the diet. Correction made according to partial digestibility (Livesey, 1990).

$\S$ For a treatment period of $1-7 \mathrm{~d}$ and faecal collection on days $5-7$ excreted stearic acid is expected to be underestimated by $11 \%$, even with a transit time shortened by 2 d (see p. 204 and Fig. 8 ).

$\|$ As computed by the method of Finley et al. (1994b) and Peters et al. (1991).

- Heat of hydrolysis(or condensation) should have been used when computed by the method of Finley et al. (1994b) and Peters et al. (1991) in place of heat of formation suggested in previous publications. The former is assumed here to be zero $(<0.5 \%$ heat of combustion of triacylglycerol).

** More fat is excreted than stearic acid alone (see Table 4).

+ Salatrim causes a small increase in protein excretion, an energy loss at $23.6 \mathrm{~kJ} / \mathrm{g}$ protein.

H. Short-chain organic acids and glycerol combine to have a net thermogenic effect, which is deducted. Protein loss reduces gluconeogenesis and ureagenesis and so, too, the thermogenic effect, which is added. 
present calculations use a zero heat of hydrolysis for the fatty acid ester bonds, whereas previous studies erroneously used the heat of formation of water from the elements (see Table 7). Nevertheless, the value of $20 \mathrm{~kJ}(5 \mathrm{kcal}) / \mathrm{g}$ was not entirely unrepresentative (as was once supposed to be a possibility for this particular reason; Livesey et al. 2000), because several other unaccounted factors had an opposing outcome. The accurate calculation of energy values may involve taking many factors into account, as shown step-by-step in Table 7. Thus, energy values for fats determined simply by balance study may, unless care is taken, result in overestimation of the energy value, because of the nature of these sources of bias.

\section{Conclusions}

A variety of factors affect stearic acid digestion from triacylglycerols. Under normal conditions stearic acid is well digested in adult human subjects, albeit slightly less well than other longchain unsaturated and shorter saturated fatty acids. The neutral health impact of stearic acid compared with other saturated fatty acids in traditional foods cannot, therefore, be attributable only to its reduced absorption. Stearoyl-rich triacylglycerols may, nevertheless, be poorly digested, owing to the density of stearic acid in the triacylglycerol. It appears that the presence of short-chain organic acids in place of long-chain fatty acids increases the stearoyl density, and so promotes poor digestion of stearic acid. Further, short-chain organic acids are readily hydrolysed from the triacylglycerol, leaving a product with a higher stearoyl density, which further attenuates stearic acid digestion. Replacement of unsaturated long-chain fatty acids with saturated long-chain fatty acids in a stearoyl triacylglycerol will also attenuate the digestion of the stearic acid, owing to increased long-chain acyl density. However, this factor will also elevate the melting point and cause the triacylglycerol to become hard, whereas replacement with short-chain organic acids retains a low melting point and keeps the fat soft. Thus, by varying the ratio of short- : long-chain acids, the physical property of the fat can be varied while retaining a low digestibility of stearic acid.

Although soap formation is a major cause of the reduced digestion of free stearic acid, under normal circumstances this factor does not appear to contribute to the reduced digestion of the stearoyl-rich triacylglycerols; rather, poor digestion of tri-, di- and monostearoyl triacylglycerols is the dominant cause, with increasing stearic acid content resulting in markedly reduced digestibility, independently of the amount ingested.

The digestibility of stearic acid in cocoa butter in human subjects remains unclear, but whole cocoa butter fat is comparatively well digested, suggesting that its stearic acid is also well digested. Stearic acid from the triacylglycerol OOS that occurs in cocoa butter is well digested, but diacetylstearoylglycerol (the major component of Salatrim 23CA) is apparently not well digested, which points to short-chain fatty acids (which are, themselves, readily digested), as an important factor in the triacylglycerol structure causing reduced stearoyl digestion. This situation is also particularly evident when butyric acid replaces oleic acid in distearoyl triacylglycerols. The role of short-chain organic acids is presumed to be that they are located on the surface of the lipid matrix, pointing into the aqueous medium where they are readily hydrolysed, and causing stearic acid in the remaining molecule (originally pointing into the lipid matrix) to submerge, where it remains difficult to digest.

The digestive tracts of the rat, the dog and man do not appear to be capable of dissolving the lipid matrix and emulsifying and digesting high-melting-point stearoyl-rich triacylglycerols. Pre vivo solubilisation of tristearin at above its melting point temperature in low-melting-point oils suggests that, in addition to indigestible triacylglycerol molecules, microcrystalline 
structure is a cause of resistance to digestion. However, this cannot be the case for Salatrims, which readily melt at body temperature.

Thus, many factors contribute to the observed apparent digestibility of stearic acid from dietary triacylglycerols. Although various studies show a variation in this value when derived from different dietary sources of stearic acid, many of the relevant factors that appear to affect this variation were not evaluated or controlled; a conclusion that absorption is strictly a function of intake level is, therefore, not warranted. Accordingly, the reduced absorption of stearic acid observed from consumption of Salatrim is more likely to be a result of its structure and the physical properties of its hydrolysis products in the gastrointestinal tract, and not of the Salatrim intake level per se.

For regulatory purposes, the available fat contents of cocoa butter, Salatrim 23CA and tristearin are calculated to be $0.93,0.33$ and $0.15 \mathrm{~g} / \mathrm{g}$ respectively, with energy values of $36.5 \mathrm{~kJ}$ $(8.7 \mathrm{kcal}) / \mathrm{g}, 20 \mathrm{~kJ}(5 \mathrm{kcal}) / \mathrm{g}$, and $6 \mathrm{~kJ}(1.5 \mathrm{kcal}) / \mathrm{g}$ respectively, although additional information would be welcome on tristearin. Available fat and energy value will probably vary with blending, particularly for tristearin, and so these are values for the fats 'as manufactured'. The stearoyl density for Salatrim 23CA is $0.57 \mathrm{~g}$ stearoyl/g product; certain other members of the Salatrim family of fats are expected to have similar or lower energy and available fat values, for example Benefat-1 $(0.57 \mathrm{~g} / \mathrm{g})$, Benefat-1H $(0.61 \mathrm{~g} / \mathrm{g})$ and Benefat-M $(0.70 \mathrm{~g} / \mathrm{g})$. Benefat-3 has a stearoyl density of $0.49 \mathrm{~g} / \mathrm{g}$ due to the use of only butyric acid as the short-chain organic acid (in place of the smaller acetate and propionate). This factor may increase its net metabolisable energy value, but is not expected to affect its long-chain fat value. The actual availability of the long-chain fat in Salatrim 23CA is less than that indicated by its available energy value : general energy value for fat $(20: 37(\mathrm{~kJ} / \mathrm{kJ})$ or $5: 9(\mathrm{kcal} / \mathrm{kcal}))$.

Finally, the use of stearic acid as the principal determinant of the energy availability from poorly-digestible stearoyl-rich triacylglycerols may lead to overestimation of their energy values, as several other factors need to be taken into account. Thus, previous methods for the estimation of energy values based on fatty acid composition and apparent digestibility of selected fatty acids may be prone to error.

\section{Acknowledgements}

The author is grateful to Dr K. C. Hayes (Brandeis University, Waltham, MA, USA) for written comments on stearic acid digestion prior to writing the review, to Dr M. H. Auerbach (DaniscoCultor, Ardsley, NY, USA) for providing original data on Salatrim 23CA, from which was calculated related variances in tables and figures and allowed identification of outlying data, and to Dr J. W. Finley (Nabisco, East Hanover, NJ, USA) for information regarding mineral intakes in the same study.

\section{References}

Allen LH, Reynolds WL \& Margen S (1979) Polyethylene glycol as a quantitative fecal marker in human nutrition experiments. American Journal of Clinical Nutrition 32, 427-440.

Apgar JL, Shively CA \& Tarka SM (1987) Digestibility of cocoa butter and corn oil and their influence on fatty acid distribution. Journal of Nutrition 117, 660-665.

Arnschink L (1890) Versuche uber die resorption verschiedener Fette aus dem Darmkanale (Study of the resorption of different fats from the gastrointestinal tract). Zeitschrift für Biologie 26, 434-451.

Atwater WO \& Bryant AP (1900) The Availability and Fuel Value of Food Materials. Connecticut (Storrs) Agricultural Experimental Station Bulletin 18. Storrs, CT: Connecticut (Storrs) Agricultural Experimental Station. 
Baer DJ, Rumpler WV, Miles WM, Fahey GC (1997) Dietary fibre decreases the metabolisable energy content and nutrient digestibility of mixed diets fed to humans. Journal of Nutrition 127, 579-586.

Bergstedt SE, Bergstedt JL, Fujimoto K, Mansbach C, Kritchevsky D \& Tso P (1991) Effects of glycerol tripalmitate and glycerol trioleate on intestinal absorption of glycerol tristearate. American Journal of Physiology 261, G239G247.

Bergstedt SE, Hayashi H, Kritchevsky D \& Tso P (1990) A comparison of the absorption of glycerol tristearate and glycerol trioleate by rat small intestine. American Journal of Physiology 259, G386-G393.

Bezard J \& Sawadogo KA (1983) The glyceride structure of perirenal fatty tissue in rats supplied with peanut-oil diet. Reproductive Nutrition and Development 23, 65-80.

Bonanome A \& Grundy SM (1988) The effect of dietary stearic acid on plasma cholesterol and lipoprotein levels. New England Journal of Medicine 318, 1244-1248.

Bonanome A \& Grundy SM (1989) Intestinal absorption of stearic acid after consumption of high fat meals in humans. Journal of Nutrition 119, 1556-1560.

Boyd OR, Crum CL \& Lyman JF (1932) The absorption of calcium soaps and the relation of dietary fat to calcium utilisation in the white rat. Journal of Biological Chemistry 95, 29-41.

Bracco U (1994) Effects of triglyceride structure on fat absorption. American Journal of Clinical Nutrition 60, 1002s1009s.

Brink EJ, Haddeman E, de Fouw NJ \& Weststrate JA (1995) Positional distribution of stearic acid and oleic acid in the triacylglycerol and dietary calcium concentration determines the apparent absorption of these fatty acids in rats. Journal of Nutrition 125, 2370-2387.

Carroll KK \& Richards JF (1958) Factors affecting digestibility of fatty acids in the rat. Journal of Nutrition 64, $411-424$.

Cheng ALS, Morehouse MG \& Deuel HJ Jr (1949) The effect of the level of dietary calcium and magnesium on the digestibility of fatty acids, simple triglycerides, and some natural and hydrogenated fats. Journal of Nutrition 37 , $237-250$

Cockett ME \& Deuel HJ (1947) A comparison of the coefficients of digestibility and the rate of absorption of several natural and artificial fats as influenced by melting point. Journal of Nutrition 33, 187-194.

Codex Alimentarius (1991) Codex Standard for Formula Foods for Use in Weight Control Diets. Codex Standard 181.

Cotton PB (1972) Non-dietary lipid in the intestinal lumen. Gut 13, 675-681.

Cummings JH \& Wiggins HS (1976) Transit through the gut measured by analysis of a single stool. Gut 17, $219-223$.

Davignon J, Simmonds WJ \& Ahrens EH (1968) Usefulness of chromic oxide as an internal standard for balance studies in formula-fed patients and for assessment of colonic function. Journal of Clinical Investigation 47, $127-138$.

Decker EA (1996) The role of stereospecific saturated fatty acids positions on lipid nutrition. Nutrition Reviews 54, $108-110$.

Demarne Y, Sacquet E, Lecourtier M-J \& Flanzy J (1979) Comparative study of endogenous fecal fatty acids in germfree and conventional rats. American Journal of Clinical Nutrition 32, 2027-2032.

DeMichelle SJ \& Karlstad MD (1995) Short-chain triglycerides in clinical nutrition. In Physiological and Clinical Aspects of Short-chain Fatty Acids, pp. 538-559 [JH Cummings, JL Rombeau, and T Sakata, editors]. Cambridge: Cambridge University Press.

Denke MA, Fox MM \& Schulte MC (1993) Short-term dietary calcium fortification increases fecal saturated fat content and reduces serum lipids in men. Journal of Nutrition 123, 1047-1053.

Denke MA \& Grundy SM (1991) Effects of fats high in stearic acid on lipid and lipoprotein concentrations in men. American Journal of Clinical Nutrition 54, 1036-1040.

Dougherty RM, Allman MA \& Iacono JM (1995) Effects of diets containing high and low amounts of stearic acid on plasma lipoproteins fractions and faecal fatty acid excretion of men. American Journal of Clinical Nutrition 61, $1120-1128$.

Drenick EJ (1961) The influence of ingestion of calcium and other soap-forming substances on faecal fat. Gastroenterology 41, 242-244.

Emken EA (1994) Metabolism of dietary stearic acid relative to other fatty acids in human subjects. American Journal of Clinical Nutrition 60, 1023s-1028s.

Emken EA, Adlof RO, Rohwedder WK \& Gully RM (1993) Influence of linoleic acid on desaturation and uptake of deuterium-labelled palmitic and stearic acids in humans. Biochimica et Biophysica Acta 1170, 173-181.

Eyssen H, Piessens-Denef M \& Parmentier G (1972) Role of the cecum in maintaining $\Delta^{5}$-steroid- and fatty acidreducing activity of the rat intestinal microflora. Journal of Nutrition 102, 1501-1511.

Filer LJ, Mattson FH \& Fomon SJ (1970) Triglyceride configuration and fat absorption by the human infant. Journal of Nutrition 99, 293-298.

Finley JW, Klemann LP, Leveille GA, Otterburn MS \& Walchak CG (1994a) Caloric availability of SALATRIM in rats and humans. Journal of Agricultural and Food Chemistry 42, 495-499.

Finley JW, Leveille GA, Dixon RM, Walchak CG, Sourby JC, Smith RE, Francis KD \& Otterburn MS (1994b) Clinical assessment of SALATRIM, a reduced calorie triacylglycerol. Journal of Agricultural and Food Chemistry 42, $581-596$.

Finley JW, Leveille GA, Dixon RM, Walchak CG, Sourby JC, Smith RE, Francis KD \& Otterburn MS (1994c) Correction. Journal of Agricultural and Food Chemistry 42, 2982.

Food and Drug Administration (1996) Food labelling: nutrient content claims pertaining to the available fat content of food. Docket numbers 96N-0421 and 94P-0453. Federal Register 61, 67243-67260. 
Grande F, Anderson JT \& Keys A (1970) Comparison of effects of palmitic and stearic acids in the diet on serum cholesterol in man. American Journal of Clinical Nutrition 23, 1184-1193.

Grundy SM (1994) Influence of stearic acid on cholesterol metabolism relative to other long-chain fatty acids. American Journal of Clinical Nutrition 60, 986s-990s.

Hashim SA \& Babayan VK (1978) Studies in man of partially absorbed dietary fats. American Journal of Clinical Nutrition 31, 273s-276s.

Hayes JR, Finley JW \& Leveille GA (1994a) In vivo metabolism of SALATRIM fats in the rat. Journal of Agricultural and Food Chemistry 42, 500-514.

Hayes JR, Pence DH, Scheinbach S, D’Amelia RP, Klemann LP, Wilson NH \& Finely JW (1994b) Review of triacylglycerol digestion, absorption and metabolism with respect to SALATRIM triacylglycerols. Journal of Agricultural and Food Chemistry 42, 474-483.

Henry RJ (1964) Clinical Chemistry: Principles and Technics, pp. 873-883. New York: Harper \& Rowe.

Hoagland R \& Snider GG (1943) Digestibility of certain higher saturated fatty acids and triglycerides. Journal of Nutrition 26, 255-260.

Hoak JC (1994) Stearic acid, clotting, and thrombosis. American Journal of Clinical Nutrition 60, 1050s-1054s.

Jensen C, Buist NRM \& Wilson T (1986) Absorption of individual fatty acids from long-chain or medium chain triglycerides in very small infants. American Journal of Clinical Nutrition 43, 745-751.

Katan MB, Zock PL \& Mensink RP (1994) Effects of fats and fatty acids on blood lipids in humans: an overview. American Journal of Clinical Nutrition 60, 1017s-1022s.

Klemann LP, Finley JW \& Leveille GA (1994) Estimation of the absorption coefficient of stearic acid in Salatrim fats. Journal of Agricultural and Food Chemistry 42, 484-488.

Koizumi N, Fujii M, Ninomiya R, Inoue Y, Kagawa T \& Tsukamoto T (1983) Studies on transitory laxative effects of sorbitol and maltitol. I: Estimation of $50 \%$ effective dose and maximum non-effective dose. Chemosphere 12, 4553.

Kritchevsky D (1994) Stearic acid metabolism and atherogenesis: history. American Journal of Clinical Nutrition 60, $997 \mathrm{~s}-1001 \mathrm{~s}$.

Langworth CF \& Holmes AD (1917) Digestibility of Some Vegetable Fats. USDA Bulletin no. 505. Washington, DC: Government Printing Office.

Lentner C, Lauffenburger T, Guncaga J, Dambacher MA \& Haas HS (1975) The metabolic balance technique: a critical reappraisal. Metabolism 24, 461-471.

Lewis GT, Partin HC \& Fla M (1954) Fecal fat on an essentially fat free diet. Journal of Laboratory and Clinical Medicine 44, 91-93.

Liener IE (editor) (1994) A collection of papers on 'SALATRIM'. Journal of Agricultural and Food Chemistry

42, $432-604$.

Livesey G (1990) Energy values of unavailable carbohydrates and diets: an inquiry and analysis. American Journal of Clinical Nutrition 51, 617-637.

Livesey G, Buss D, Coussement P, Edwards DG, Howlett J, Jonas D, Kleiner JE, Muller D \& Sentko A (2000) Suitability of traditional energy values for novel foods and food ingredients. Food Control 11, 249-289.

McDonell B (1997) FDA questions Nabisco's proposed digestibility coefficient for Salatrim. Food Labelling and Nutrition News February issue, $11-12$.

Mattil KF \& Higgins JW (1945) The relationship of glyceride structure to fat digestibility. Journal of Nutrition 29 , $255-260$.

Mattson FH (1959) The absorbability of stearic acid when fed as a single or mixed triglyceride. Journal of Nutrition $\mathbf{6 9}$, $338-342$.

Mattson FH, Nolen GA \& Webb MR (1979) The absorbability by rats of various triglycerides of stearic and oleic acid and the effects of dietary calcium and magnesium. Journal of Nutrition 109, 1682-1687.

Merrill AL \& Watt BK (1973) The Energy Values of Foods, Basis and Derivation. USDA Handbook 74. Washington, DC: Government Printing Office.

Ministry of Agriculture, Fisheries and Foods (1990) Intake of Intense and Bulk Sweeteners in the UK. Food Surveillance Paper no. 29, London: H.M. Stationery Office.

Mitchell DC, McMahon KE, Shively CA, Apgar JL \& Kris-Etherton PM (1989) Digestibility of cocoa butter and corn oil in human subjects: a preliminary study. American Journal of Clinical Nutrition 50, 983-986.

Mitchell WD, Fyfe T \& Smith DA (1968) The effect of oral calcium on cholesterol metabolism. Journal of Atherosclerosis Research 8, 913-922.

Narine SS \& Marangoni AG (1999a) Microscopic and rheological studies of fat crystal networks. Journal of Crystal Growth 199, 1315-1319.

Narine SS \& Marangoni AG (1999b) The difference between cocoa butter and Salatrim lies in the microstructure of the fat crystal network. Journal of the American Oil Chemists' Society 76, 7-13.

Nolen GA (1981) Biological evaluation of hydrogenated rapeseed oil. Journal of the American Oil Chemists' Society 58, $31-37$.

Olubajo O, Marshall MW, Judd JT \& Adkins JT (1986) Effect of high- and low-fat diets on the bioavailability of selected fatty acids, including linoleic acid, in adult men. Nutrition Research 6, 931-955.

Pearson TA (editor) (1994a) Proceedings of the Symposium on Metabolic Consequences of Stearic Acid Relative to other Long-chain Fatty Acids. American Journal of Clinical Nutrition 60, Suppl. 6s. 
Pearson TA (editor) (1994b) Proceedings of the Symposium on Chocolate in Perspective: Cocoa Butter, a Unique Saturated Fat. American Journal of Clinical Nutrition 60, Suppl. 6s.

Peters JC, Holcolmb BN, Hiller LK \& Webb DR (1991) Caprenin 3. Absorption and caloric value in adult humans. Journal of the American College of Toxicology 10, 357-367.

Ranhotra GS, Gelroth JA \& Leinen SD (1998) Energy value of a fat high in stearic acid. Journal of Food Science 63, $363-365$.

Rhee SK, Kayani AJ, Ciszek A \& Brenna JT (1997) Desaturation and interconversion of dietary stearic and palmitic acids in human plasma and lipoproteins. American Journal of Clinical Nutrition 65, 451-458.

Saunders D, Sillery J \& Chapman R (1988) Effect of calcium carbonate and aluminium hydroxide on human intestinal function. Digestive Diseases and Sciences 33, 409-413.

Shahkhalili Y, Duruz E \& Archeson K (2000) Digestibility of cocoa butter from chocolate in humans: a comparison with corn-oil. European Journal of Clinical Nutrition 54, 120-125.

Sharpe SJ \& Robinson MF (1970) Intermittent and continuous faecal markers in short-term metabolic studies in young women. British Journal of Nutrition 24, 489-500.

Sklan D \& Budowski P (1972) Formation of linoleic acid in the rat caecum. British Journal of Nutrition 28, $457-462$.

Small DM (1991) Physical properties of fatty acids and their extracellular and intracellular distribution. In Polyunsaturated Fatty Acids in Human Nutrition, pp. 25-29 [U Bracco and R Deckelbaum, editors]. New York: Raven Press.

Small DM (1992) The effect of glyceride structure on absorption and metabolism. Annual Review of Nutrition 11, 413434.

Softly BJ, Huang AS, Finley JW, Petersheim M, Yarger RG, Chrysam MM, Wieczorek RL, Otterburn MS, Manz A \& Templeman GJ (1994) Composition of representative SALATRIM fat preparations. Journal of Agricultural Food Chemistry 42, 461-467.

Tomarelli RM, Meyer BJ, Weaber JR \& Bernhart FW (1968) Effects of positional distribution on the absorption of fatty acids of human milk and infant formulas. Journal of Nutrition 95, 583-590.

Wang C-S (1986) Hydrolysis of dietary glycerides and phosphoglycerides: fatty acid and positional specificity of lipases and phospholipases. In Fat Absorption, vol. 1, pp. 83-117 [A Kukis, editor]. Boca Raton, FL: CRC Press.

Webb JPW, James AT \& Kellock TD (1963) The influence of diet on the quality of faecal fat in patients with and without steatorrhoea. Gut 4, 37-41.

Wiggins HS, Howell KE, Kellock TD \& Stalder J (1969) The origins of faecal fat. Gut 10, 400-403.

Woollett LA \& Dietschy JM (1994) Effect of long-chain fatty acids on low-density-lipoprotein-cholesterol metabolism. American Journal of Clinical Nutrition 60, 991s-996s.

World Health Organization (1999) Evaluation of Certain Food Additives and Contaminants. Forty-ninth Report of the Joint FAO/WHO Expert Committee on Food Additives. Technical Report Series no. 884. Geneva: WHO. 